\title{
Productivity Dispersion and Plant Selection in the Ready-Mix Concrete Industry
}

\author{
Allan Collard-Wexler *† \\ Economics Department, NYU Stern
}

September 15, 2007

\begin{abstract}
Plant level productivity in the ready-mix concrete sector is highly dispersed, whereby a plant in the $75^{\text {th }}$ percentile of the distribution produces $25 \%$ more output than a plant in the $25^{t h}$ percentile. Is the magnitude of this dispersion real or simply an artifact of measurement error? Moreover, why don't inefficient producers exit the industry? Using a dynamic model of entry and exit, I find that a low productivity plant's profits are $\$ 300000$ less than a high productivity plant, i.e. a plant in the $25^{\text {th }}$ percentile of productivity plant produces $20 \%$ less than a plant in the $75^{t h}$ percentile of productivity which uses the same inputs. Exit of innefficient producers is slowed by two factors. First, sunk costs are quite large in the ready-mix concrete industry, so a firm will remain in the industry even when it is currently making substantial losses. Second, plant productivity is very volatile, so current productivity is a weak signal of future profitability.
\end{abstract}

${ }^{*}$ This paper is part of my Ph.D. dissertation at Northwestern University under the supervision of Robert Porter, Michael Whinston, Aviv Nevo and Shane Greeenstein. I thank Lynn Riggs, Jan de Loecker, Pat Bajari and Carlos Serrano for their insights, and seminar participants at McGill University, CAED 2006 conference, the Toronto Industry Dynamics Conference, the 2007 IIOC Conference and the 2007 North American Summer meetings of the Econometric Society. Financial support from the Fonds Québecois sur la Recherche et la Société et Culture and the Center for the Study of Industrial Organization at Northwestern University is gratefully acknowledged. The research in this paper was conducted while the author was a Special Sworn Status researcher of the U.S. Census Bureau at the Chicago Census Research Data Center. Research results and conclusions expressed are those of the author and do not necessarily reflect the views of the Census Bureau. This paper has been screened to insure that no confidential data are revealed. Support for this research at the Chicago RDC from NSF (awards no. SES-0004335 and ITR-0427889) is also gratefully acknowledged.

wexler@stern.nyu.edu 


\section{Introduction}

A society's ability to provide for its members is determined in large part by the productivity of its plants. A presumption shared by many economists is that plant-level efficiency is governed by common inputs such as technology and the availability of capital or educated workers. Yet there can be considerable differences in plant productivities for an identical product within the same market. For instance, in the ready-mix concrete industry, a plant in the $75^{\text {th }}$ percentile of productivity has $25 \%$ the output as one in the $25^{\text {th }}$ percentile if both plants use the same inputs.1 Why do we observe such a large dispersion in productivity? Moreover, is this dispersion real, or is it an artifact of measurement error. Does competition drive out inefficient plants from an industry?

This paper has two goals. First, I estimate the effect of low productivity on plant profitability based on entry and exit decisions. I find that average profits of a plant below the median level of productivity are $\$ 316,000$ lower than those of a plant above the median, where the average plant ships approximately $\$ 1.8$ million dollars of concrete each year. There is substantial productivity dispersion. A plant in the $75^{\text {th }}$ percentile ships $20 \%$ more concrete than a plant in the $25^{\text {th }}$ percentile (if both plants use the same inputs), but far less the 4 for 1 difference observed in the data. Second, I ask whether government policies can influence the distribution of plant-level productivity. Would entry subsidies boost average plant productivity by encouraging the entry of more productive producers? Would more severe economic fluctuations "cleanse" the market of inefficient producers?

Sunk costs explain why inefficient plants are not displaced by potentially more productive entrants. Absent sunk costs, a new entrant could adopt the best technology and displace an incumbent who is less productive. Entry would insure that every plant is on efficient given current technology. However, sunk costs create a wedge between the productivity cutoff at which an entrant decides to enter the market (say $\underline{\rho^{e}}$ ) and the lower cutoff at which

\footnotetext{
${ }^{1}$ Productivity is defined as the residual in the regression of $\log$ value added on $\log$ salaries and log total assets with year dummies.
} 


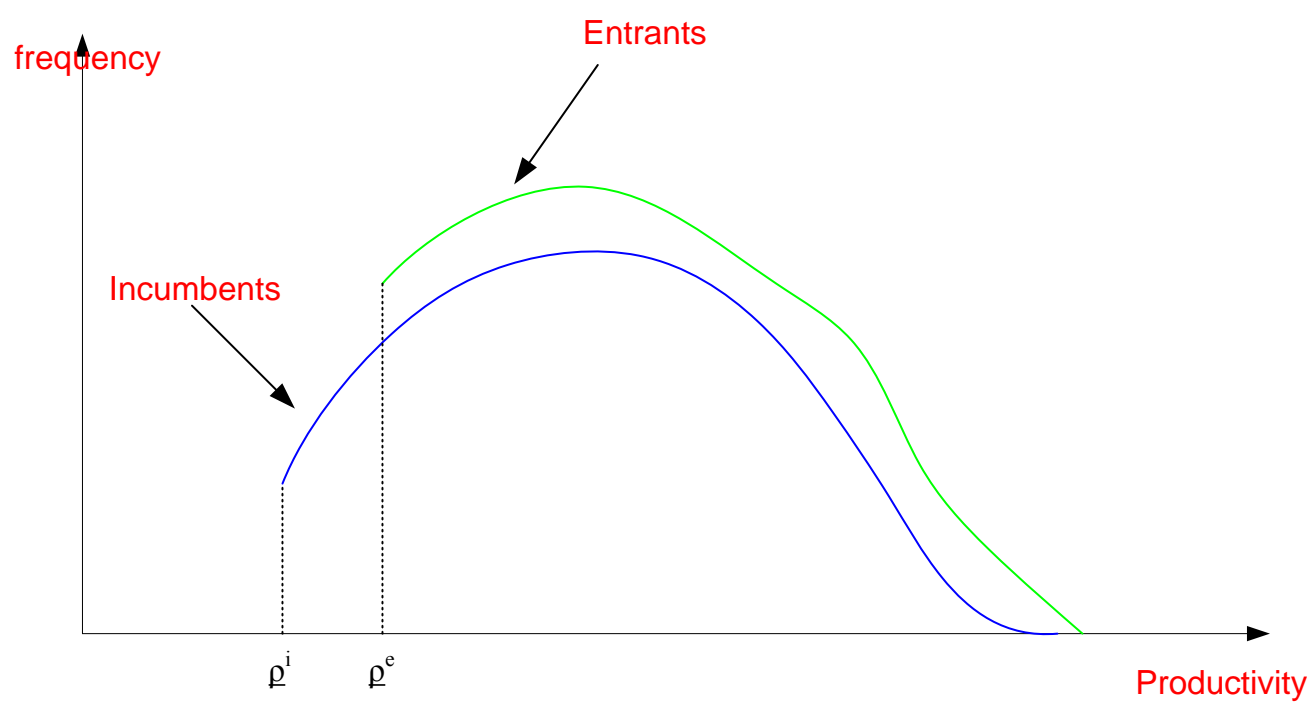

Figure 1: Sunk Costs make Incumbents have a lower productivity cutoff than Entrants.

an incumbent exits (say $\rho^{i}$ ). Figure 1 displays the productivity distributions of incumbents and entrants when there are sunk costs. An inefficient producer will remain active at a productivity level for which it would never have considered entering is not profitable ( if productivity is $\rho \in\left(\rho^{i}, \rho^{e}\right)$ ).

Furthermore, do productivity differences persist over time? If productivity is independent across time, a plant's efficiency level does not affect it's decision to remain in the market, since current productivity provides no information on future productivity. The less persistent is productivity, the less informative current productivity is about future profits. Finally, competition helps eliminate inefficient producers. Fiercer competition reduces profits for all plants in the industry, forcing out low productivity incumbents. I model the selection process in the ready-mix concrete industry, and I estimate a dynamic model of entry and exit that incorporates competitive considerations and the evolution of plant-level productivity.

In Section 2, I review the literature on plant selection and oligopoly dynamics. In Section 3, I describe the data on ready-mix concrete plants and my measure productivity. Section 5 provides basic empirical evidence 
for plant selection. Section 6 presents the empirical model of entry and exit, while Section 7 discuses results from the model.

\section{Literature}

I draw on three litteratures. The first concerns the evolution of productivity at the plant level, the second on structural estimation of productivity, and the third on the estimation of models of dynamic oligopoly models.

\subsection{Productivity and Plant Selection}

Theoretical models of industry dynamics are explored by Jovanovic (1982) and Hopenhayn (1992). They study the effect of firms learning about their productivities on the entry and exit process and an industry's steady-state. These theoretical models have been influential in the macroeconomic literature but have received limited empirical scrutiny, a gap which I attempt to redress.

Syverson (2004) documents productivity dispersion in the ready-mix concrete industry using data from the U.S. Census Bureau. Productivity is defined as the residual of the regression of log output on log salaries and $\log$ assets. The magnitude of productivity dispersion is robust to several different measures of productivity, including defining output as total cubic yards of ready-mix concrete produced. Syverson conjectures that competition plays a key role in eliminating unproductive plants, which limits the dispersion of productivity. The empirical evidence to support this conjecture looks at the distribution of productivity in large and small markets, where market size is determined by the density of construction activity. Productivity is more dispersed in in small markets. Moreover, there is a smaller share of low productivity plants in large markets than small ones. Competition appears to truncate the distribution of productivity from below by driving out inefficient plants. My goal is to explore the mechanism for plant selection in more detail, instead of focusing on the cross-sectional implications of plant selection considered by Syverson (2004). 
Lucia, Haltiwanger, and Krizan (1998) investigate the micro-foundations of aggregate productivity growth. They decompose changes in aggregate productivity into three effects: productivity changes within the plant, entry of more efficient producers and exit of unproductive ones and reallocation of output from inefficient plants to efficient ones. Foster, Haltiwanger and Krizan find that most productivity improvements can be traced to reallocation of output to more efficient plants, and not the exit of inefficient producers. I llustrates the effect of policies such as entry subsidies and demand fluctuations on the evolution of aggregate productivity, a task which is beyond the reach of Lucia, Haltiwanger, and Krizan (1998).

Foster, Haltiwanger, and Syverson (2005) investigate the role of a plant's profitability and productivity in the exit decision. Profitability differs from productivity since a plant in a concentrated market experiencing high demand can make large profits without being particularly good at producing ready-mix concrete. Foster, Haltiwanger and Syverson find that plants with either high productivity or profitability are less likely to exit, and that it is difficult to separate the effects of these two measures. Dunne, Klimek, and Roberts (2006) also look at entry and exit decisions of several geographically differentiated producers (including ready-mix concrete). Plants that were built by firms with previous industry experience have lower exit rates than those of newer entrants. It is difficult to gage if these other characteristics of firms can explain the dispersion of productivity present in the data.

\subsection{Structural Estimates of Productivity}

To estimate production functions we need to account for two biases. First, firms may observe their productivity shock before choosing inputs, which is known as the simultaneity problem. Simultaneity will lead us to overstate the importance of flexible inputs such as labor which will be correlated with the productivity shock, and understate the importance of more permanent inputs such as capital. Second, the distribution of productivity is truncated since low productivity firms are more likely to shut down. Thus firms which have a higher likelihood of exiting the industry (such as small firms) could 
also have a more selected productivity distribution. To correct for both the simultaneity and selection problems Olley and Pakes (1996) propose a control function correction. The basic idea behind this procedure is that we can proxy for the unobserved productivity shock by noticing that this shock is a function of the firm's investment decision conditional on the state it is in. For instance, more productive firms will invest more. If I put investment into a production function regression, I can control for factors that are correlated with higher productivity, but should not lead directly to higher production. Levinsohn and Petrin (2003) extend the Olley and Pakes (1996) approach, using material inputs as a proxy instead of investment. These material inputs controls have the advantage of having far more continuous variation in the data, while investment data is quite lumpy. Ackerberg, Frazer, and Caves (2006) propose an integrated framework for thinking about control function estimates of production functions using either material or investment control or the literature on dynamic panel models. I use this approach in my estimates for production functions since it offer more flexibility in specifying the moments conditions that I use. I also take the control function approach very literally in that I back out and analyze the firm's "true productivity".

\subsection{Estimation of Dynamic Multi-Agent Models}

Models of dynamic oligopoly pose daunting econometric challenges that require specialized solution techniques. The framework for empirical models of dynamic oligopoly was developed by Ericson and Pakes (1995), who incorpo-

rate the solution concept of Markov-Perfect Equilibrium (Maskin and Tirole (1988)). To bring this framework to data, the econometrics of dynamic discrete choice (e.g. Rust (1987)) can be used to estimate model parameters given the choices of firms. However, Rust's Nested Fixed Point algorithm is intractable for estimating all but the simplest dynamic game. Finding an equilibrium of a dynamic game is computationally intensive, since an equilibrium is a fixed point in both the agent's value function and its bestresponse policy, given that other players are also playing a best-response. 
Bajari, Benkard, and Levin (2006), Pakes, Berry, and Ostrovsky (2006) and Aguirregabiria and Mira (2006) develop techniques for estimating the parameters of a dynamic game without the computational burden associated with computing the solution to the game for each parameter vector. As Collard-Wexler (2006), I adopt the techniques developed by Aguirregabiria and Mira (2006) to estimate the parameters of the dynamic game, which impose the restriction that firms play equilibrium strategies.

\section{Data}

\subsection{Entry and Exit}

Data on Ready-Mix Concrete plants is drawn from three different data sets provided by the Center for Economics Studies at the United States Census Bureau 2 Table 1 illustrates the datasets used. The first is the Census of Manufacturing (henceforth CMF), a complete census of manufacturing plants, every five years from 1963 through 1997. The second is the Annual Survey of Manufacturers (henceforth ASM) sent to a sample of manufacturing plants (about a third for ready-mix) every non-Census year since 1973. Both the ASM and the CMF involve questionnaires that collect detailed information on a plant's inputs and outputs. The third data set is the Longitudinal Business Database (henceforth LBD) compiled from data used by the Internal Revenue Service to maintain business tax records. The LBD covers all private employers on a yearly basis since 1976. The LBD only contains employment and salary data, along with sectoral coding and certain types of business organization data such as firm identification. Construction data is obtained by selecting all establishments from the LBD in the construction sector (SIC 15-16-17) and aggregating them to the county level.

Production of ready-mix concrete for delivery predominantly takes place at establishments in the ready-mix sector corresponding to either NAICS

\footnotetext{
${ }^{2}$ In Collard-Wexler (2006) I discuss the construction of entry and exit data in further detail.
} 


\begin{tabular}{llll} 
& CMF & ASM & LBD \\
\hline Data Set & Census of Manufacturing & Annual Survey of Manufacturing & Longitudinal Business Database \\
Collection & Questionnaire & Questionnaire & IRS Tax Data \\
Years & 1963, 67, 72, 77, 82, 87, 92,97 & $1972-2000$ & $1976-1999$ \\
Coverage & All Manufacturing Firms & $30 \%$ of Manufacturing Firms & All Private Sector Firms \\
Variables & Input and Output Data including & Input and Output Data & Employment and Payroll \\
& materials and product trailers & & and Birth/Death data \\
Plant Identifiers & PPN, CFN & PPN, CFN & LBDNUM, CFN
\end{tabular}

Table 1: Description of Census Data Sources

(North American Industrial Classification) code 327300 or SIC (Standard Industrial Classification) code 3273.

\subsection{Longitudinal Linkages}

To construct longitudinal linkages, I use the Longitudinal Business Database Number, as developed by Jarmin and Miranda (2002). This identifier is constructed from CFN, employer ID and name and address matches of all plant in the LBD. Since the LBD is the basis for mailing Census questionnaires to establishments, virtually all plants present in the ASM/CMF are also in the LBD (starting in 1976), allowing a uniform basis for longitudinal matching. To identify plant entry and exit, I use Jarmin and Miranda (2002)'s plant birth and death measures. Jarmin and Miranda identify entry and exit based on the presence of a plant in the I.R.S.'s tax records. 3

Over the sample period there are about 350 plants births and 350 plants deaths each year compared to 5000 continuers. Turnover rates and the total number of plants in the industry are fairly stable over the last 30 years. Table A2 displays characteristics of ready-mix concrete plants: they employ 26 workers on average, and each sold about 3.2 million dollars of concrete in 1997, split evenly between material costs and value added. However, these averages mask substantial differences between plants. Most notably, the distribution of plant size is heavily skewed, with few large plants and many small ones, indicated by the fact that more than $5 \%$ of plants have 1 employee, while less than $5 \%$ of plants have more than 82 employees. Moreover,

\footnotetext{
${ }^{3}$ If I a plant changes ownership, I do not treat this as an exit event since the cost of changing the management at a plant should be much lower than the cost of building a plant from scratch.
} 
Table A1 shows continuing firms are twice as large as either entrants(births) or exitors(deaths), measured by capitalization, salaries or shipments.

\subsection{Measuring Productivity}

To measure productivity I use information on a plant's inputs and outputs contained in the Annual Survey of Manufacturing (ASM) and the Census of Manufacturing (CMF). One issue is that I do not have annual data for all ready-mix concrete plants. The ASM is a questionnaire that samples about $\frac{1}{3}$ of ready-mix concrete producers each year. 4 My model of productivity and competition requires the productivities of all plants in a market, since the productivities of plant's competitors is an important component of the model. Since the ASM samples a third of plants in the ready-mix concrete industry, the probability that I have data on all plants in market is decreasing in the number of plants in a market. Thus the sample of markets is severely truncated in ASM years. For these reasons, I do not use ASM data in the estimation of the dynamic model, and I instead rely on data from the CMF 5

The CMF is a questionnaire sent to all manufacturing plants every 5 years. Since the CMF is a complete census, I have data on all plants in each market. This allows the data to be used to look at the relationship between competition and productivity. However, since the CMF samples plants every 5 years, I can only look at a firm's entry/exit decision the year following a Census year.

A large fraction of input and output data in the ASM and CMF is imputed by the Census Bureau. I flag the data which is possibly imputed, and I discuss the details of imputed data in Appendix B.

\footnotetext{
${ }^{4}$ The ASM selects plants based on plant size, including all plants with more than 250 workers but covering very few small ready-mix producers. This employment based stratified sampling presents a problem. First, if I select plants based on employment I can create selection bias in the measurement of productivity since I have no information on smaller producers. In the production function regressions presented in Table A10 on page 48 the coefficient on capital drops from 0.323 (in column 4) to 0.041 (in column 1) when ASM years are included. This suggests that undersampling small firms produces underestimates of the importance of capital, I may observe too little variation in capital stock to estimate this coefficient.

${ }^{5}$ The ASM data is suitable for single-agent models of entry and exit, since the omission of small producers is less likely to cause bias.
} 
Plant efficiency plays a large role in the decision to continue operating. Plants do not report productivity directly. Instead, productivity has to be inferred based on a plant's reported outputs and inputs. I estimate productivity (TFP) as the residual from the log-linear production function OLS regression:

$$
\begin{aligned}
y_{i}^{t}(\text { total value of shipments })= & \beta_{l} l_{i}^{t}(\text { salaries })+\beta_{k} k_{i}^{t}(\text { capital }) \\
& +\beta_{m} m_{i}^{t}(\text { cost of materials })+A^{t}+\rho_{i}^{t}
\end{aligned}
$$

where a lower case variable denotes the logarithm of the actual variable, $A_{t}$ is the intercept of the production function for each year (so that year to year changes in technology do not affect the dispersion of productivity) and $\rho_{i}^{t}$ is a plant's productivity. I deflate all items measured in dollars by the consumer price index (CPI) published by the BLS for the given year ${ }^{6}$

In Appendix C I discuss using different measures of output, namely value added, cubic yards of concrete or total shipments in estimating the total dispersion of productivity. I use total shipments as a measure of output since I explain why unprofitable firms do not exit the ready-mix concrete industry, not why firms that produce little concrete per unit of input stay in the industry. Firms which can charge a higher markup, due to either higher quality production or market power, should stay in the industry.

\section{Control Function Estimates of Productivity}

Productivity is typically estimated using the log-linear or Cobb-Douglas production function:

$$
y_{i t}(\text { sales })=\beta_{0}+\beta_{l} l_{i t}+\beta_{k} k_{i t}+\beta_{m} m_{i t}+\rho_{i t}
$$

\footnotetext{
${ }^{6}$ It is important to deflate data measured in dollars since the log-linear production function is not linearly homogeneous if the sum of the capital and labor coefficients differs from one, and thus is sensitive to rescaling variables.

${ }^{7} \mathrm{CPI}$ data downloaded from ftp://ftp.bls.gov/pub/special.requests/cpi/cpiai.txt, accessed May 52006.
} 
where estimated firm productivity is $\rho_{i t}$, the "unexplained" component of total sales. Estimated productivity $\rho_{i t}$ conflates both true differences in productivity and errors in the measurement of either inputs or outputs. In particular, since by definition measurement error is uncorrelated with "true productivity" differences then TFP will overestimate the degree of productivity dispersion in an industry.

The production function that both Olley and Pakes (1996) and Ackerberg, Frazer, and Caves 2006) consider is the following:

$$
y_{i t}(\text { sales })=f\left(l_{i t}, k_{i t}, m_{i t}\right)+\omega_{i t}+\epsilon_{i t}
$$

The goal is to separate "true" productivity differences between firms, denoted as $\omega_{i t}$, from measurement error denoted as $\epsilon_{i t}$.

\subsection{First-Stage}

To identify the extent of measurement error, I impose structure on the way firms make their investment and materials choices. Suppose that the firm's state $s_{i t}$ is composed of both the firm's capital stock $k_{i t}$, the firm's "true" productivity level $\omega_{i t}$ and other states such the level of demand in the market or the number of competitors in a market which I will refer to as $x_{i t}$.

$$
s_{i t}=\left\{k_{i t}, \omega_{i t}, x_{i t}\right\}
$$

Suppose that either investment $\left(i_{i t}\right)$, labor or material input demand functions are strictly increasing in $\omega_{i t}$ conditional on the rest of the state $\left(\left\{k_{i t}, x_{i t}\right\}\right)$. I can rewrite the investment function as:

$$
i_{i t}=i\left(s_{i t}\right)=i\left(k_{i t}, \omega_{i t}, x_{i t}\right)
$$

Under the assumption that $i(\cdot)$ is strictly increasing in $\omega$, then this function 
can be inverted 8

$$
\omega_{i t}=i^{-1}\left(i_{i t} \mid k_{i t}, x_{i t}\right)=h\left(i_{i t}, k_{i t}, x_{i t}\right)
$$

It is then possible to replace $\omega_{i t}$ in equation (3) by $h\left(i_{i t}, k_{i t}, x_{i t}\right)$. This yields:

$$
\begin{aligned}
y_{i t} & =f\left(l_{i t}, k_{i t}, m_{i t}\right)+h\left(i_{i t}, k_{i t}, x_{i t}\right)+\epsilon_{i t} \\
& =\phi\left(l_{i t}, k_{i t}, m_{i t}, i_{i t}, x_{i t}\right)+\epsilon_{i t}
\end{aligned}
$$

I can identify the extent of measurement error in the first stage by performing a non-parameteric regression of the log of sales on labor, materials and capital. Table 2 presents the first stage non-parameteric regression.

Denote the estimated $\hat{\phi}(\cdot)$ function. The measurement error component of TFP can be computed as:

$$
\epsilon_{i t}=y_{i t}-\hat{\phi}\left(l_{i t}, k_{i t}, m_{i t}, i_{i t}, x_{i t}\right)
$$

Notice that the essential difference between the $\phi(\cdot)$ function and the production function $f(\cdot)$ is that $\phi$ includes not only inputs into the production function but also other variables that should be correlated with higher productivity but uncorrelated with unmeasured inputs into the production process.

\subsection{Second-Stage}

In the second stage I recover a plant's "true productivity". Suppose that a plant's true productivity follows a first-order Markov process ${ }^{9}$ Then tom-

\footnotetext{
${ }^{8}$ Olley and Pakes $(1996)$ provide conditions under which the investment policy will be strictly increasing in productivity. If the is imperfectly competitive, then it is no longer true that the investment function will be strictly increasing.

${ }^{9}$ The assumption that a firm's productivity follows a first-order Markov process can easily be relaxed. For instance, if we assume that a firm's productivity follows a secondorder Markov Process, then the evolution of productivity is governed by:

$$
\omega_{i t}=g\left(\omega_{i t-1}, \omega_{i t-2}\right)+\xi_{i t}
$$
}




\begin{tabular}{|c|c|c|c|c|c|c|}
\hline \multirow[b]{2}{*}{ Log Shipments } & \multicolumn{2}{|c|}{ OLS } & \multicolumn{2}{|c|}{ Fixed Effect } & \multicolumn{2}{|c|}{ First-Stage ACF } \\
\hline & Coefficient & S.E. & Coefficient & S.E. & Coefficient & S.E. \\
\hline Constant & 1.709 & $(0.033)$ & 1.896 & $(0.058)$ & 1.0780 & $(0.2003)$ \\
\hline Salaries & 0.271 & $(0.005)$ & 0.238 & $(0.007)$ & 1.0136 & $(0.0676)$ \\
\hline Total Assets & 0.070 & $(0.004)$ & 0.034 & $(0.004)$ & 0.1270 & $(0.0231)$ \\
\hline Cost of Materials & 0.595 & $(0.005)$ & 0.596 & $(0.008)$ & 0.0840 & $(0.0909)$ \\
\hline Investment & & & & & 0.0398 & $(0.0231)$ \\
\hline Log RMC Plants in County & & & & & -0.0283 & $(0.0405)$ \\
\hline Squared Salaries & & & & & 0.1214 & \\
\hline Squared Assets & & & & & -0.0044 & \\
\hline Squared Investment & & & & & 0.1936 & \\
\hline Squared Materials & & & & & 0.0016 & \\
\hline Squared Competition & & & & & 0.0237 & \\
\hline Salaries * Assets & & & & & 0.0065 & \\
\hline Salaries * Investment & & & & & 0.0033 & \\
\hline Salaries * Multi-Unit & & & & & -0.0068 & \\
\hline Salaries * Materials & & & & & -0.3316 & \\
\hline Salaries $*$ Competition & & & & & 0.0223 & \\
\hline Assets $*$ Materials & & & & & -0.0249 & \\
\hline Assets * Competiton & & & & & 0.0014 & \\
\hline Assets * Multi-Unit & & & & & 0.0032 & \\
\hline Assets $*$ Investment & & & & & 0.0008 & \\
\hline Materials * Investment & & & & & -0.0118 & \\
\hline Materials * Competition & & & & & -0.0175 & \\
\hline Materials * Multi-Unit & & & & & -0.0014 & \\
\hline Investment $*$ Multi-Unit & & & & & 0.0028 & \\
\hline Investment $*$ Competition & & & & & -0.0014 & \\
\hline Competition $*$ Multi-Unit & & & & & -0.0137 & \\
\hline Cubed Salaries & & & & & 0.0023 & \\
\hline Cubed Assets & & & & & 0.0009 & \\
\hline Cubed Investment & & & & & 0.0004 & \\
\hline Cubed Materials & & & & & -0.0011 & \\
\hline Cubed Competition & & & & & -0.0041 & \\
\hline Year Effect & $\mathrm{X}$ & & $\mathrm{X}$ & & $\mathrm{X}$ & \\
\hline Plant Fixed Effect & & & $\mathrm{X}$ & & & \\
\hline $\mathrm{F}$ & 5355 & & 1247.46 & & 2491 & \\
\hline $\mathrm{R} 2$ & 0.9413 & & 0.876 & & 0.97 & \\
\hline Plants & & & 4256 & & & \\
\hline Observations & 9049 & & 9049 & & 4338 & \\
\hline
\end{tabular}

Table 2: OLS, Fixed Effect and First-Stage Regression of the Ackerberg-Caves-Frazer procedure. 12 
morow's productivity is generated by:

$$
\omega_{i t}=g\left(\omega_{i t-1}\right)+\xi_{i t}
$$

where $\xi_{i t}$ is the innovation to today's productivity. To compute $\xi_{i t}$, I perform a non-parametric regression of $\omega_{i t}$ on $\omega_{i t-1}$, i.e. $\omega_{i t}=\hat{f}\left(\omega_{i t-1}\right)+\xi_{i t} 10$

Since $\xi_{i t}$ is unobserved by the firm at the time at which it decides how much to invest, then $\xi_{i t}$ and $k_{i t}$ should be uncorrelated. Likewise, since a firm chooses materials based on today's $\omega_{i t}$, not based on tomorrow's productivity draw, then $\xi_{i t}$ should be uncorrelated with either today's labor inputs or material inputs. Combining these moment conditions together (and which ever other moment conditions the researcher could choose), we obtain:

$$
\mathbf{E} \xi_{i t}\left(\begin{array}{c}
l_{i t} \\
m_{i t} \\
k_{i t+1}
\end{array}\right)=0
$$

Which allows us to form an analogue estimator using the GMM criterion. First, stack the data as:

$$
\begin{aligned}
\mathbf{X}(\beta) & =\left(\begin{array}{c}
\vec{\xi}_{1 t}(\beta) \\
\ldots \\
\vec{\xi}_{N t}(\beta)
\end{array}\right) \\
\mathbf{Z} & =\left(\begin{array}{c}
\vec{l}_{t} \\
\vec{m}_{t} \\
\vec{k}_{t+1}
\end{array}\right)
\end{aligned}
$$

The GMM criterion using the weighting matrix $\left(\mathbf{Z}^{\prime} \mathbf{Z}\right)^{-1}$ is:

We can proceed with the same estimation routine with $\xi_{i t}$ derived from this equation.

${ }^{10}$ In practice, I simply use a polynomial expansion as my $\hat{f}(\cdot)$ function:

$$
\omega_{i t}=\alpha_{0}+\alpha_{1} \omega_{i t-1}+\alpha_{2} \omega_{i t-1}^{2}+\alpha_{3} \omega_{i t-1}^{3}+\xi_{i t}
$$

Of course, I could have used a Naradaya-Watson estimator instead of a polynomial expansion, but there is no reason to expect a large difference in the final production function estimates. 


\begin{tabular}{l|rrrr}
\hline \hline & \multicolumn{2}{|c}{ OLS } & \multicolumn{2}{c}{ Ackerberg, Caves and Frazer } \\
Log Shipments & Coefficient & Standard Error & Coefficient & Standard Error \\
\hline Constant & 1.709 & $(0.033)$ & & \\
Salaries & 0.271 & $(0.005)$ & 0.186 \\
Assets & 0.070 & $(0.004)$ & 0.018 \\
Materials & 0.595 & $(0.005)$ & 0.753 \\
& & & $\mathrm{X}$ \\
Year Effects & $\mathrm{X}$ & & \\
& & & \\
GMM Criterion & 9072 & & \\
Observations & & & \\
\hline \hline
\end{tabular}

Table 3: Ackerberg, Caves and Frazer estimates of productivity.

$$
Q(\beta)=\left(\mathbf{X}(\beta)^{\prime} \mathbf{Z}\right)\left(\mathbf{Z}^{\prime} \mathbf{Z}\right)^{-1}\left(\mathbf{X}(\beta)^{\prime} \mathbf{Z}\right)^{\prime}
$$

I find $\beta_{l}, \beta_{k}$ and $\beta_{m}$ which minimize the GMM criterion $Q(\beta)$ using a Simulated Annealing algorithm. These parameters are presented in Table 3. Table ?? presents Olley-Pakes style estimates of the production function, where output is defined in terms of value added instead of total shipments. For the Olley-Pakes results, I find little difference in the estimated capital coefficient, indicating that the simultaneity problem is not a large problem in the ready-mix concrete data I use. However, I still find that "true productivity" dispersion is much lower, once I eliminate measurement error.

Then "true productivity" can be computed as:

$$
\omega_{i t}=\hat{\phi_{i t}}-\hat{\beta}_{l} l_{i t}-\hat{\beta_{k}} k_{i t}-\hat{\beta_{m}} m_{i t}
$$

\subsection{Measures of Dispersion}

My main goal is to explain the dispersion of plant-level efficiency, the fact that plants that use the same bundle of inputs have different levels of output. Dispersion can be gaged by $R^{2}$ 's in Table A11 s production function regressions. To express the relative disperion of productivity, I look at the dispersion that would occur if all plants used the same bundle of inputs, 
but brought their own productivity residual. The rational behind this technique is that I want to look at the sources of TFP dispersion, but I want to eliminate differences in output that are due solely to differences in the use of inputs 11

The predicted output of a plant that uses the median levels of capital, labor and materials (denoted as $k_{50}, l_{50}$ and $m_{50}$ respectively), but brings it's $q^{\text {th }}$ quantile of the productivity residual can be computed as:

$$
\hat{y}^{\rho_{q}}=\beta_{l} l_{50}+\beta_{k} k_{50}+\beta_{m} m_{50}+\rho_{q}
$$

Likewise, I can obtain the predicted output of a plant which brings it's $q^{\text {th }}$ quantile of "true productivity", but has the median level of measurement error:

$$
\hat{y}^{\omega_{q}}=\beta_{l} l_{50}+\beta_{k} k_{50}+\beta_{m} m_{50}+\omega_{q}+\epsilon_{50}
$$

Finally, I obtain the contribution of measurement error to productivity dispersion by looking at the quantiles of output when I change measurement error:

$$
\hat{y}^{\epsilon_{q}}=\beta_{l} l_{50}+\beta_{k} k_{50}+\beta_{m} m_{50}+\omega_{50}+\epsilon_{q}
$$

Table 4 presents the dispersion of Output due to TFP dispersion, true productivity, and measurement error. The interquartile range for TFP is about $\$ 500000$, or $25 \%$ of output. However, when we look at the dispersion due to "true productivity", the interquartile range is only $\$ 300000$, or $15 \%$ of output. What is happening here is that the interquartile dispersion of measurement error is $\$ 400000$, or $20 \%$ of output. Thus the dispersion of TFP is due to an equal mixture of true productivity differentials and measurement error. Note that the sum of productivity and measurement error dispersion will be higher that TFP dispersion if these two are negatively correlated.

\footnotetext{
${ }^{11} \mathrm{I}$ am implicitly foreclosing the discussion on productivity differences that are due to using inefficient bundles of inputs.
} 


\begin{tabular}{r|rrr} 
& \multicolumn{4}{|c}{$\begin{array}{c}\text { Dispersion due to } \\
\text { Percentile }\end{array}$} & TFP $\left(\rho_{q}\right)$ & Productivity $\left(\omega_{q}\right)$ & Measurement $\left(\epsilon_{q}\right)$ \\
\hline \hline $10 \%$ & 1.7 & 1.8 & 1.8 \\
$25 \%$ & 1.8 & 1.9 & 1.9 \\
$50 \%$ & 2.0 & 2.0 & 2.0 \\
$75 \%$ & 2.3 & 2.2 & 2.3 \\
$90 \%$ & 2.9 & 2.3 & 2.6
\end{tabular}

Table 4: Dispersion of Predicted Output due to TFP dispersion, true productivity, and measurement error (in millions of dollars).

\subsection{Persistence of Productivity}

The current level of productivity provides two pieces of information to the firm. Low productivity reduces current profits since the plant produces less concrete for a given level of inputs. If productivity is persistent, low productivity also implies lower future profits. The more persistent is productivity the more informative current productivity is about future profits. I estimate the transition process for productivity non-parametrically as:

$$
\hat{P}^{\rho}\left[\rho^{t} \in a \mid \rho^{t-1} \in b\right]=\frac{\sum_{t=2}^{T} \sum_{i=1}^{I} 1\left(\rho_{i}^{t} \in a, \rho_{i}^{t-1} \in b\right)}{\sum_{t=2}^{T} \sum_{i=1}^{I} 1\left(\rho_{i}^{t-1} \in b\right)}
$$

where $1(\cdot)$ is the indicator function.

To compute the year to year transition process for productivity I use yearly data on productivity from the ASM. I cannot use the CMF because it only samples plants every 5 years. Moreover, the estimator in equation (10) does not count plants that exit in the next period or that are not in the ASM. ASM plants and continuers are typically larger and more productive than the average plant in the CMF, so I may underestimate the likelihood of transiting to the low productivity state. This would explain the fact that plants are more likely to end up in the high productivity state in the transition process reported in Table 5 .

I place measured productivity into two bins: a plant is either above or below median productivity in a given year. Table 5 shows the estimated transition probabilities for productivity. Notice that the productivity dis- 
To

From

\begin{tabular}{l|rc} 
& Low Productivity & High Productivity \\
\hline Out & 0.49 & 0.51 \\
Low Productivity* & 0.71 & 0.29 \\
High Productivity** & 0.21 & 0.79
\end{tabular}

* Low Productivity is productivity below the median for the year

*High Productivity is productivity above the median for the year

Table 5: Productivity exhibits limited persistence.

tribution for entering plants are no different than for incumbents. Entrants do not have a productivity advantage or disadvantage with respect to incumbents. Surprisingly, a plant with high productivity today has a $20 \%$ probably of being a low productivity plant next year. Why is there so much volatility in plant productivity?

In Appendix D I discuss decomposing the components of productivity volatility. Even if I use a much less volatile version of capital based on constructing capital stock using investment flows and depreciation, I still get comparable autocorrelations of productivity.

Dispersion of plant productivity may be due to different vintages of ready-mix plants. Older plants were build with less efficient technology and compete with newer vintages. Competing vintages can result in the wide dispersion of productivity observed in the data. However, the readymix concrete industry is unusual in the lack of technological change over the last 50 years. The machines and trucks used to produce ready-mix concrete 50 years ago are remarkably similar to those in use today. Table 6 shows the volume of concrete produced per worker hour has increased by less than 10\% between 1967 and 1997. Because aggregate productivity has increased

\footnotetext{
${ }^{12}$ Note that serially uncorrelated measurement error could cause both productivity dispersion and productivity volatility. Using the proxy variable methods from Olley and Pakes (1996) and Ackerberg, Frazer, and Caves (2006) yields subtantially more persistence in the estimated productivity transition process.
} 
very slowly, the assumption that the ready-mix concrete industry is near its steady-state is plausible, and thus dispersion seems to characterize the industry's equilibrium.

\section{$5 \quad$ Evidence for Plant Selection}

Before estimating the structural model, I provide evidence of the mechanisms of plant selection. These results inform which features of the data can identify parameters of the structural model. There are four margins on which I observe the process of plant selection: exit, growth, entry and competition.

\subsection{Inefficiency encourages exit}

The first mechanism of plant selection is the exit of inefficient producers. Plant exit provides the cleanest evidence of selection since an incumbent's productivity can be measured in the year before exiting. Moreover, while plant's exit is determined both by productivity within the plant and competition in the market, plant-level factors typically provide greater explanatory power.

Figure A1 shows the death rate for plants in each quintile of productivity. A plant in the second quintile of productivity is three times as likely to exit as a plant in the top quintile. However, a plant in the lowest quintile of productivity is significantly less likely to exit than a plant in the second quintile. The non-monotonicity of the exit hazard disappears when I control for other plant characteristics and drop hot imputes and administrative records. Table A4 reports probit regressions of the probability of exit on plant productivity, ownership and employment, when I drop imputed records. In column III of Table A4, a plant with all variables at their means, but in the bottom quintile of productivity has an exit rate of $3.75 \%$ while a plant in the top quintile has an exit rate of $1.51 \%$. Productivity data for plants with unusually low productivity may be unreliable. Moreover, the effect of high productivity is similar to the effects of either ownership and size, the most important determinants of plant exit identified in Collard-Wexler 


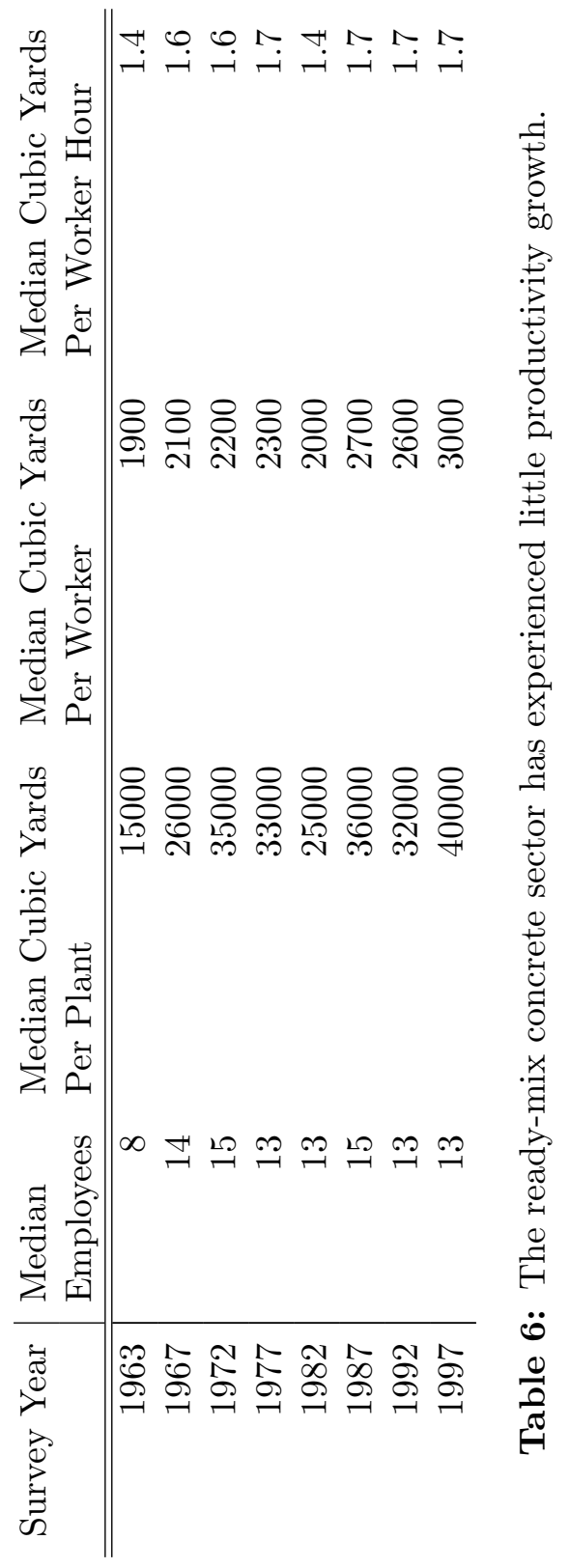


To

From

\begin{tabular}{ll|ccc} 
& & Out & Small & Large \\
\hline Out & & $99.1 \% \diamond$ & $0.9 \%$ & $0.0 \%$ \\
Small $^{+}$ & Low Productivity* & $8.5 \%$ & $86.2 \%$ & $5.3 \%$ \\
& High Productivity** & $3.8 \%$ & $89.9 \%$ & $6.3 \%$ \\
Large $^{++}$ & Low Productivity & $2.3 \%$ & $15.2 \%$ & $82.4 \%$ \\
& High Productivity & $1.8 \%$ & $13.2 \%$ & $84.9 \%$
\end{tabular}

+ Small: Plant with fewer than 15 employees.

++ Big: Plant with at least 15 employees.

*Low Productivity: Productivity below the median for the year.

**High Productivity: Productivity above the median for the year.

$\diamond$ Number of Entrants is 6 minus the number of active firms in the county.

Table 7: Low productivity plants are less likely to grow than high productivity plants.

(2006).

At first glance, the relationship between productivity and exit is somewhat disappointing. Consider as a benchmark a model in which plants compete in a perfectly competitive market. In this model, a plant below a certain threshold of productivity exits with certainty. The weakness of the relationship between exit and productivity explains the wide dispersion of productivity between plants: inefficient producers are slowly selected out. Another reason for modest effect of productivity is the role of reallocation, a low productivity plants are more likely to shrink. Table 7 illustrates this effect, as plants which have low productivity are $2 \%$ less likely to end up as large plants (more than 15 employees) in the next period than small plants. Moreover, in two periods smaller plants have twice the exit rate of large plants. Thus the increased hazard of exit in two periods will be attributed to small plant size, while the plant's low efficiency that caused it to shrink in the first place. 


\subsection{Productivity Deters Entry}

Markets with more efficient producers should have fewer plant births, since entrants face tougher post-entry competition. Table A6 present a countyfixed effect negative binomial regression on the number of entrants in a county per year. A market which has only high productivity plants (where productivity is decomposed into terciles) can expect 0.5 fewer plant births per year than a market with only medium productivity plants. Since the average market has 10 entrants per year, this corresponds to a $5 \%$ decrease in the volume of entry. As in Table A1, there is a non-monotonic relationship between productivity and entry since Table A6 indicates that there is significantly more entry in a market with medium productivity plants than in a market with low productivity plants. The presence of large plants, defined as a plant with more than 20 employees, which are larger in part because of higher productivity, reduces the number of entrants by 1.5 plants per year, a $15 \%$ decrease in the entry rate. This is a significantly positive effect of the number of competitors on entry and a marginally negative effect of construction employment. Entry reacts to profitability which may be more closely tracked by the number of firms which can operate rather than construction employment.

\subsection{Competitive Markets are More Productive}

Competition lowers profitability for all firms in a market. Less efficient producers should be more likely to exit in a market with many competitors. This link between productivity and market size is thoroughly investigated by Syverson (2004). I confirm his results in Table A7, which shows that there is a higher fraction of productive plants in large markets.

\section{Model}

My model is similar to the model in Collard-Wexler (2006). A crucial difference is that plant productivity cannot be altered by the firm. Denote the 
firm's state $s_{i}^{t}$ as:

$$
s_{i}^{t}=\{\underbrace{a_{i}^{t-1}, \rho_{i}^{t}}_{x_{i}^{t}: \text { Observed State Unobserved State }}, \underbrace{\varepsilon_{i}^{t}}_{\text {Obs }}\}
$$

where $a_{i}^{t-1}$ is the firm's choice to have an active plant in the next period, $\rho$ indicates if the plant's productivity is above or below the median and $\varepsilon_{i}^{t}$ are other firm states such as credit constraints, which are not observable in my data. A plant can either be high or low productivity. A plant has high productivity denoted $\bar{\rho}$ if its productivity is above the median for the year. A plant has low productivity denoted $\underline{\rho}$ if its productivity is at or below the median for the year. The state of the market $s^{t}$ is the collection of firm states $s_{i}^{t}$ and the demand state $M^{t}$, taken as the number of construction employees in the county: $s^{t}=\left\{s_{1}^{t}, s_{2}^{t}, \ldots, s_{N}^{t}, M^{t}\right\}$. When a firm chooses to operate a ready-mix concrete plant it takes into account both its own productivity and the productivities of its competitors. Plant-level productivity $\rho_{i}^{t}$ follows an exogenous first-order Markov process, with transition probabilities given by Table 5. Finally, demand $M^{t}$ follows the first order Markov process that was estimated as Collard-Wexler (2006).

I make two important assumptions on the evolution of productivity. First, I assume that firms cannot control their productivity. In my model, productivity refers to total factor productivity, not to output per worker. The purchase of better machines increases the firm's capital stock, not its Solow residual. Second, in contrast with Jovanovic (1982) model, I assume that firms do not learn about their productivity as they age. In the readymix concrete industry there is no evidence that a firm's age has an impact on its exit decision. 13 Figure A2 shows that the exit hazard decreases gently with age. Younger firms could be less likely to exit if they delay shutting down in order to accumulate information on their underlying productivity. In a Bayesian learning model, older firms use a higher productivity cutoff for exiting than younger firms. If younger firms have less information

\footnotetext{
${ }^{13}$ In contrast, Abbring and Campbell (2003) find evidence that bars in Texas face considerable uncertainty about their profitability in their first year in operation.
} 


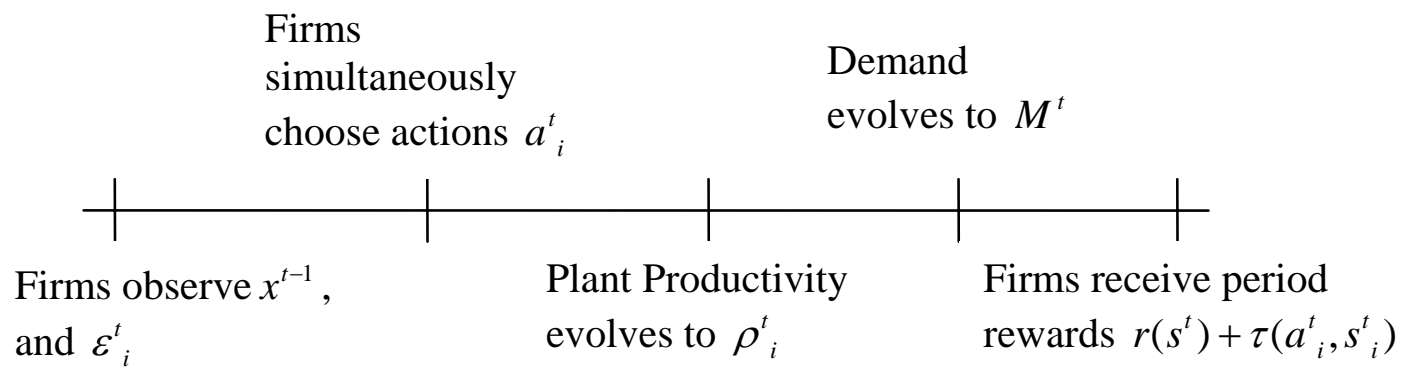

Figure 2: Timing of the game within each period.

about their true productivity level, a younger firm has greater option value than an older firm, for a given realization of productivity,. Figure A3 shows that the productivities of the $25^{t h}, 50^{t h}$ and $75^{\text {th }}$ percentile plants do not increase with age, indicating that firms face little uncertainty on the permanent component of their productivities. Moreover, Figure A4 shows the average number of employees at a plant rises dramatically in a plant's first year, and subsequently grows slowly: ${ }^{14}$

Figure 2 illustrates the timing assumptions of the model within each period. First, unobserved states $\varepsilon_{i}^{t}$ are privately observed by firms. Firms simultaneously choose whether to operate a ready-mix concrete plant in the next period. Productivity and demand then evolve to their new levels. Finally, firms receive period profits.

\footnotetext{
${ }^{14}$ Pakes and Ericson (1998) discuss the empirical content of the passive learning models in the Jovanovic (1982) tradition. They show that one of the few empirical implications of the passive learning model is that the expected firm size is increasing in the previous size of the firm. Pakes and Ericson (1998) do not have data on plant level productivity, so their tests of the passive and active learning models are not based on plant-level productivity.
} 
I parametrize the firm's reward function as:

$$
\begin{aligned}
r\left(a^{t+1}, x^{t+1} \mid \theta\right)= & a_{i}^{t+1} \underbrace{\theta_{1}}_{\text {Fixed Cost }}+\underbrace{\theta_{2} 1\left(\rho_{i}^{t+1}=\bar{\rho}\right)}_{\text {Fixed Cost if High Productivity }} \\
& +\underbrace{\theta_{3} M^{t+1}}_{\text {Demand }}+\underbrace{\theta_{4} M^{t+1} 1\left(\rho_{i}^{t+1}=\bar{\rho}\right)}_{\text {Demand if High Productivity }} \\
& +\underbrace{\theta_{5} g\left(\sum_{k \neq i} a_{k}^{t+1}\right)}_{\text {Competition }}
\end{aligned}
$$

where $a^{t+1} \in\{0,1\}$ is the firm's choice to be active in the next period (i.e. the entry decision) and $x^{t+1}$ are observed states. Note that higher productivity does not have a direct effect on competitors in this model. Instead, productivity has an indirect effect on the profits of competitors because more productive firms are more likely to stay in the industry.

\subsection{Conditional Choice Probabilities}

The econometrician cannot directly observe strategies, since these depend not only on the vector of observable state characteristics, $x^{t}$, but also on the vector of unobserved state characteristics, $\varepsilon^{t}$. However, I can observe conditional choice probabilities, the probability that firms in observable state $x^{t}$ choose action profile $a^{t}$ denoted as $p: X \times A \rightarrow[0,1]$. These probabilities are related to strategies as:

$$
p\left(a^{t} \mid x^{t}\right)=\int_{\varepsilon^{t}} \prod_{i=1}^{N} \sigma_{i}\left(\left\{x^{t}, \varepsilon^{t}\right\}, a_{i}^{t}\right) g^{\varepsilon}\left(\varepsilon^{t}\right) d \varepsilon^{t}
$$

where $g^{\varepsilon}($.$) is the probability density function of \varepsilon$. Without adding more structure to the model, it is impossible to relate the observables in this model, the choice probabilities $p\left(a^{t} \mid x^{t}\right)$, to the underlying parameters of the reward function. Denote the set of conditional choice probability associated with an equilibrium as $P=\left\{p\left(a^{t} \mid x^{t}\right)\right\}_{x^{t} \in X, a^{t} \in A}$, the collection of conditional choice probabilities for all states and action profiles. To identify the parameters, I place restrictions on unobserved states, similar to those 
used in the Rust (1987) framework for dynamic single-agent discrete choice.

Assumption 1 (Additive Separability) The sum of period rewards and transition costs is additively separable in observed $\left(x^{t}\right)$ and unobserved $\left(\varepsilon^{t}\right)$ states.

This assumption implies that $\zeta\left(\varepsilon^{t}, x^{t}, a^{t}, \theta\right)=\zeta\left(\varepsilon^{t}, a^{t}, \theta\right)$. So that $\zeta$ does not vary with the observed state $x^{t}$.

Assumption 2 (Serial Independence) Unobserved states are serially independent, i.e. $\operatorname{Pr}\left(\varepsilon^{t} \mid \varepsilon^{k}\right)=\operatorname{Pr}\left(\varepsilon^{t}\right)$ for $k \neq t$.

Serial independence allows the conditional choice probabilities to be expressed as a function of the current observed state, $x^{t}$, and action profile, $a^{t}$, without loss of information due to omission of past and future states and actions. Formally:

$$
\operatorname{Pr}\left(a^{t} \mid x^{t}\right)=\operatorname{Pr}\left(a^{t} \mid x^{t},\left\{x^{t-1}, x^{t-2}, \ldots, x^{0}\right\},\left\{a^{t-1}, a^{t-2}, \ldots, a^{0}\right\}\right)
$$

for any $k \neq t$, any state $x^{t}$, and action profile, $a^{t}$, since no information is added to equation (12) that would change the value of the integral over $\varepsilon$.

Denote the set of conditional choice probabilities as $\mathbf{P}=\left\{p\left(a_{i}, x\right)\right\}_{\left\{a_{i} \in A, x \in X\right\}}$, i.e. the probability that a firm will decide to enter the market (play $a_{i}=1$ ) given that it is in state $x$. The expected profits for firms given that conditional choice probability set $\mathbf{P}$ is being played is denoted $\pi^{\mathbf{P}}\left(x^{\prime}, x_{i}\right)$. Expected profits are computed using the following expression:

$\pi^{\mathbf{P}}\left(x^{\prime}, x_{i}\right)=\sum_{\left(a_{1}^{t}, a_{2}^{t}, \ldots, a_{N}^{t}\right)} r\left(\left[a_{1}^{t+1}, a_{2}^{t+1}, \ldots, a_{N}^{t+1}\right], x^{t+1} \mid \theta\right) \prod_{i=1}^{N} P\left(a_{i}^{t+1} \mid x^{t+1}\right)-\tau\left(a_{i}^{t+1}, x_{i} \mid \theta\right)$

where $\tau\left(a_{i}^{t+1}, x_{i}\right)$ are the sunk costs of entering a market if a firm enters the market this period and was out of the market in the last period.

The firm's value function is defined as:

$$
V^{\mathbf{P}}(x)=\sum_{x^{\prime} \in X}\left(\pi^{P}\left(x^{\prime}, x_{i}\right)+E\left(\varepsilon_{i} \mid P\right)+\beta V^{\mathbf{P}}\left(x^{\prime}\right)\right) \operatorname{Pr}\left[x^{\prime} \mid x\right]
$$


where state to state transition probabilities are given by:

$$
\operatorname{Pr}\left[x^{\prime} \mid x\right]=\hat{D}\left[M^{\prime} \mid M\right] \prod_{i=1}^{N}\left(P^{\mathbf{P}}\left[a_{i}^{\prime} \mid x\right] \hat{P}^{\rho}\left[\rho_{i}^{\prime} \mid x_{i}\right]\right)
$$

and the evolution of productivity is governed by:

$$
P^{\rho}\left[\rho_{i}^{\prime} \mid x_{i}\right]=\left\{\begin{array}{c}
\hat{P}^{\rho}\left[\rho_{i}^{\prime} \mid \rho_{i}\right] \text { if } a_{i}^{t-1}=1 \\
\hat{P}^{\rho}\left[\rho_{i}^{\prime} \mid \text { out }\right] \text { if } a_{i}^{t-1}=0
\end{array}\right.
$$

Notice that both the demand transition probabilities $\hat{D}\left[M^{\prime} \mid M\right]$ and the productivity transition probabilities $\hat{P}^{\rho}\left[\rho_{i}^{\prime} \mid x_{i}\right]$ are directly estimated from the data without reference to the structural model. Demand is placed into 10 discrete bins $B_{i}=\left[b_{i}, b_{i+1}\right)$, where the $b_{i}$ 's are chosen so that each bin contains the same number of demand observations. Making the model more realistic by increasing the number of bins above 10 has little eff ect on estimated coefficients, but lengthens computation time significantly. The level of demand within each bin is set to the mean demand for observations in this bin, i.e. $\operatorname{Mean} b(i)=\frac{\sum_{l=1}^{L} M_{l} 1\left(M_{l} \in B_{i}\right)}{\sum_{l=1}^{L} 1\left(M_{l} \in B_{i}\right)}$, where $L$ indexes observations in the data, and the $D$ matrix is estimated using a bin estimator $\hat{D}[i \mid j]=\frac{\sum_{(l, t)} 1\left(M_{l}^{t+1} \in B_{i}, M_{l}^{t} \in B_{j}\right)}{\sum_{(l, t)} 1\left(M_{l}^{t} \in B_{j}\right)}$. Likewise, the productivity transition process $\hat{P}^{\rho}\left[\rho_{i}^{\prime} \mid x_{i}\right]$ is estimated using a bin estimator, and estimated transition process is reported in Table 5 on page 17.

I assume that the private information unobservable $\varepsilon_{i}^{t}$ is distributed as an i.i.d. logit. The expected value $\varepsilon_{i}^{t}$ given that firms have conditional choice probabilities given by $\mathbf{P}$ is:

$$
E(\varepsilon \mid \mathbf{P})=\sum_{a_{i} \in A} \ln \left(P\left[a_{i} \mid x\right]\right)+\gamma
$$

where $\gamma \approx 0.5772$ is Euler's constant. 


\subsection{Computational Aside}

The computational algorithm in Collard-Wexler (2006) is modified to accommodate the exogenous evolution of firm productivity. First, the state to state transition probabilities $\operatorname{Pr}\left[x_{i}^{t+1} \mid x^{t}\right]$ are computed as:

$$
\begin{aligned}
& \operatorname{Pr}\left[x_{i}^{t+1} \mid x^{t}\right]=\quad P\left[\left\{a_{i}^{t+1}, \rho_{i}^{t+1}\right\} \mid x^{t}\right] \\
& =P\left[a_{i}^{t+1} \mid x^{t}\right] \operatorname{Pr}\left[\rho_{i}^{\prime} \mid \rho_{i}, x_{i}\right] \\
& =P^{\mathbf{P}}\left[a_{i}^{t+1} \mid x^{t}\right] \hat{P}^{\rho}\left[\rho_{i}^{t+1} \mid \rho_{i}, x_{i}\right]
\end{aligned}
$$

Second, the value function conditional on taking action $a_{i}$ today, $V^{\mathbf{P}}\left(a_{i}, x\right)$ is computed as:

$$
V^{\mathbf{P}}\left(a_{i}, x\right)=\sum_{\rho_{i}^{\prime}}\left(V^{\mathbf{P}}\left(\left\{a_{i}, \rho_{i}^{\prime}\right\}, x\right)+E(\varepsilon \mid P)\right) \operatorname{Pr}\left[\rho_{i}^{\prime} \mid x_{i}\right]
$$

where $V\left(x_{i}^{t+1}, x^{t}\right)$ is computed as if the firm could choose both its activity and its productivity in the next period, but does not receive any option value from the unobserved state. Throughout the entire algorithm, the firm's state take one of four value: $x_{i} \in\{1,2,3,4\}$ representing $\{($ out,$\underline{\rho}),($ out, $\bar{\rho}),($ in,,$\underline{\rho}),($ in, $\bar{\rho})\}$. This allows the use of symmetry encoding algorithms from Collard-Wexler (2006), which considerably reduce the size of the state space.

\section{Dynamic Results}

I estimate the dynamic model of entry and exit with exogenous productivity using the techniques of Aguirregabiria and Mira (2006) and Hotz and Miller (1993). Table 8 shows the baseline parameters I am using for the estimation of the model, such as a discount rate of $0.90 \%$ or the fact that I impose that there are 6 firms per market, who are either potential entrants or incumbents. 15 Table 9 presents estimates of the dynamic entry-exit

\footnotetext{
${ }^{15} \mathrm{I}$ use a discount rate of $\beta=0.9$, which is a rather high. If I had used a discount rate of say $\beta=0.95$, this would decrease the estimated sunk costs of entry since a firm enters
} 


\begin{tabular}{ll}
\hline Discount Rate & $\beta=0.90$ \\
Number of Firms per Market & $N=6$ \\
Number of Demand States & $D=10$ \\
Number of Firm States & $\#\left(x_{i}\right)=4$ \\
Number of UnEncoded States & $\# S^{u e}=40960$ \\
Number of Encoded States & $\# S^{e}=2240$ \\
\hline
\end{tabular}

Table 8: Baseline Parameters for the Dynamic Model of Entry/Exit and Productivity.

model, where column I shows estimates using the 1-step Hotz and Miller (1993) method and column II shows estimates for the Aguirregabiria and Mira (2006) model. Standard errors are computed using the Hessian of the likelihood function, where I assume that the transition probabilities are estimated without error ${ }^{16}$ I find similar results as the model of Collard-Wexler (2006), which are reproduced in Table A8 for comparison. The coefficient on the first competitor is large $(-0.66)$, while the effect of subsequent entrants is not statistically significantly different from 0 . The effect of log of county construction employment is 0.03 , similar to the effect of demand in the entry and exit model presented in Table A8. Finally, the magnitude of sunk costs is -5.5 variance units, which is similar to the coefficient found in Table A8, where sunk costs are -6.2 variance units. Note that difference can be explained in part by the lower exit rate for plants in this sample compared to the entry-exit model. Most interesting is the large effect of being a high productivity plant, with a coefficient is 1.11 variance units in the Hotz and Miller (1993) estimates and 0.86 in the Aguirregabiria and Mira (2006) estimates. This effect is far more than the effect of the first competitor on profits.

As reported in Collard-Wexler (2006), interview data indicates that the

if the net present value of future profits are greater than the sunk costs of entry. Thus using a discount rate of $90 \%$ give conservative estimates of the effect of high productivity on profitability compared to sunk costs.

${ }^{16}$ I have also estimated these standard errors using an non-parametric bootstrap which reestimates the entire model for each resample. I find no interesting differences in these bootstrapped standard errors versus the Hessian standard errors. 


\begin{tabular}{|c|c|c|c|c|}
\hline & I & s.e. & II & s.e. \\
\hline Fixed Cost Group $1 \dagger$ & 1.06 & $(0.41)$ & -0.53 & $(0.10)$ \\
\hline Fixed Cost Group 2 & 1.42 & $(0.41)$ & -0.35 & $(0.11)$ \\
\hline Fixed Cost Group 3 & 1.42 & $(0.39)$ & -0.32 & $(0.11)$ \\
\hline Fixed Cost Group 4 & 1.11 & $(0.43)$ & -0.35 & $(0.13)$ \\
\hline Decrease in Fixed Costs for High Productivity Firms & 1.19 & $(0.27)$ & 0.86 & $(0.17)$ \\
\hline Log of Construction Employment & 0.05 & $(0.02)$ & 0.03 & $(0.01)$ \\
\hline 1st Competitor* & -1.74 & $(1.11)$ & -0.61 & $(0.07)$ \\
\hline 2nd Competitor & 0.08 & $(0.20)$ & 0.07 & $(0.11)$ \\
\hline 3rd Competitor & 0.01 & $(0.20)$ & -0.07 & $(0.15)$ \\
\hline More than 3 Competitors & 0.34 & $(0.51)$ & 0.04 & $(0.10)$ \\
\hline Sunk Cost of Entry & -5.55 & $(0.09)$ & -5.45 & $(0.08)$ \\
\hline Equilibrium Conditional Choice Probabilities & & & X & \\
\hline Log-Likelihood & -3625.47 & & -3599.05 & \\
\hline Observations & 235000 & & 235000 & \\
\hline
\end{tabular}

*The effect of competition displayed is the marginal effect of each additional competitor. $\dagger$ Markets are classified into groups 1 to 4 based on the average number of plants in the market from 1976 to 1999, which is rounded to the nearest integer.

I: Hotz and Miller technique with market heterogeneity.

II: Aguirregabiria and Mira technique with market heterogeneity.

Table 9: Dynamic Entry Model with Exogenous Productivity. 


\begin{tabular}{l|rr} 
& Parameters in & Parameters in \\
& Variance Units & Dollars \\
\hline \hline Fixed Cost Group 1 & -0.53 & $\$-195,000$ \\
Fixed Cost Group 2 & -0.35 & $\$-128,000$ \\
Fixed Cost Group 3 & -0.32 & $\$-117,000$ \\
Fixed Cost Group 4 & -0.35 & $\$-128,000$ \\
Decrease in Fixed Costs for High Productivity Firms & 0.86 & $\$ 316,000$ \\
Log of Construction Employment & 0.03 & $\$ 11,000$ \\
1st Competitor & -0.61 & $\$-224,000$ \\
2nd Competitor & 0.07 & $\$ 25,000$ \\
3rd Competitor & -0.07 & $\$-25,000$ \\
More than 3 Competitors & 0.04 & $\$ 15,000$ \\
Sunk Cost of Entry & -5.45 & $\$ 2,000,000$ \\
\hline \hline
\end{tabular}

Table 10: A plant with high productivity makes about $\$ 300000$ more per year than a plant with low productivity using estimates from the model.

sunk costs of starting a ready-mix concrete plant are on the order of 2 million dollars. Thus, I can convert the coefficients expressed in variance units in Table 9 into dollars. Table 10 shows estimates expressed in dollars, where I have normalized coefficients based on the assumption that the sunk costs of entry are 2 million dollars. Yearly profits of a high productivity plant are $\$ 300000$ greater than for a low productivity plant. These are substantial differences in profitability since the median plant has shipments of about 2 million dollars per year, while rates of return on capital in the industry are on the order of $5 \%$ per year. These numbers do not match the dispersion of productivity presented in Table ??, which indicates that the differences in the profitability of plants should be on the order of several million dollars per year. The main issue is measurement error in output and input use. Measurement error artifically increases productivity dispersion in Table ??. However, measurement error has the opposite effect on the estimates of Table 9. If I misclassify a plant as having high productivity, this attenuates the effect of being a high productivity plant. Thus $\$ 300000$ is likely to be a lower bound on the effect of being a low productivity plant, while the 
estimate that a plant in the $75^{\text {th }}$ percentile of productivity has 4 times the productivity as a plant in the $25^{t h}$ percentile surely overestates the true productivity dispersion. Preliminary work using the proxy variable techniques of Olley and Pakes (1996) and Ackerberg, Frazer, and Caves (2006) decreases the magnitude of productivity dispersion by $50 \%$, separting "true" productivity dispersion which firms react to by investing more or purchasing more materials and dispersion due to measurement error. Furthermore, sunk costs presented in Table 9 are most likely overestimates. These sunk costs incorporate any persistent unobservables that induce plants to be less likely to exit. They give the impression that large sunk costs kept firms them in the industry instead of other factors, such as the ownership of a jointly operated gravel pit which supplies their concrete operations. Finally, measurement error may cause me to underestimate the persistence of plantlevel productivity. Underestimating persistence leads to overestimates of the effect of low productivity on profits, since I underestimate the effect of current productivity on the net present value of productivity in the future.

\section{Conclusion}

In the ready-mix concrete industry, plants using the same bundle of inputs produce substantially different amount of concrete. The average plant in the $75^{\text {th }}$ percentile of productivity produces four times the output of a plant in the $25^{t h}$ percentile. But, the exit rate of a plant below the median level of productivity is $3 \%$ versus an exit rate of $6 \%$ for a plant above the median. Why do these enormous differences in productivity translate into small differences in exit rates? First, in this industry, productivity has little persistence. Thus current productivity does not provide much information on the net present value of productivity over the plant's expected lifetime. Second, sunk costs slow the exit of unproductive producers, since it is costly to enter the industry. Using entry and exit information, I find a $20 \%$ difference in output between plants in the $25^{\text {th }}$ and $75^{\text {th }}$ percentile which use the same inputs. Thus, even a conservative measure of productivity dispersion finds substantial differences in productivity. An unanswered question is whether 
the magnitude of this dispersion can be reduced throught the subsidy of entry. 


\section{References}

Abbring, J. H., And J. R. CAmpbell (2003): "A Firm's First Year," Federal Reserve Bank of Chicago Working Paper, 11.

Ackerberg, D., G. Frazer, and K. Caves (2006): "Structural Estimation of Production Function," Working Paper UCLA.

Aguirregabiria, V., And P. Mira (2006): "Sequential Estimation of Dynamic Discrete Games," Econometrica, forthcoming.

Bajari, P., L. Benkard, and J. Levin (2006): "Estimating Dynamic Models of Imperfect Competition," Econometrica, forthcoming.

Collard-Wexler, A. (2006): "Demand Fluctuations and Plant Turnover in the Ready-Mix Concrete Industry," Working Paper, New York University.

Dunne, T., S. Klimek, And M. J. Roberts (2006): "Exit from regional manufacturing markets the role of entrant experience," Journal of Industrial Organisation, forthcoming.

Ericson, R., And A. Pakes (1995): "Markov-Perfect Industry Dynamics: A Framework for Empirical Work," The Review of Economic Studies, 62(1), 53-82.

Foster, L., J. C. Haltiwanger, And C. Syverson (2005): "Reallocation, Firm Turnover, and Efficiency: Selection on Productivity or Profitability?," .

Hopenhayn, H. A. (1992): "Entry, Exit, and firm Dynamics in Long Run Equilibrium," Econometrica, 60(5), 1127-1150.

Hotz, V. J., And R. A. Miller (1993): "Conditional Choice Probabilities and the Estimation of Dynamic Models," The Review of Economic Studies, 60(3), $497-529$.

Jarmin, R. S., And J. Miranda (2002): "The Longitudinal Business Database," Working Paper, Center for Economic Studies, US Census Bureau.

Jovanovic, B. (1982): "Selection and the Evolution of Industry," Econometrica, $50(3), 649-670$.

Levinsohn, J., And A. Petrin (2003): "Estimating Production Functions Using Inputs to Control for Unobservables," Review of Economic Studies, 70(2), 317341.

Lucia, F., J. Haltiwanger, and C. J. Krizan (1998): "Aggregate productivity growth: lessons from microeconomic evidence," NBER Working Paper 6803.

Maskin, E., And J. Tirole (1988): "A Theory of Dynamic Oligopoly, I: Overview and Quantity Competition with Large Fixed Costs," Econometrica, 56(3), 549569 . 
Olley, G. S., And A. Pakes (1996): "The dynamics of productivity in the telecommunications equipment industry," Econometrica, 64(6), 35.

Pakes, A., S. Berry, And M. Ostrovsky (2006): "Simple estimators for the parameters of discrete dynamic games, with entry/exit examples,", RAND Journal of Economics, forthcoming.

Pakes, A., And R. Ericson (1998): "Empirical Applications of Alternative Models of Firm and Industry Dynamics," Journal of Economic Theory, 79(1), 1-45.

Rust, J. (1987): "Optimal Replacement of GMC Bus Engines: An Empirical Model of Harold Zurcher," Econometrica, 55(5), 999-1033.

Syverson, C. (2004): "Market Structure and Productivity: A Concrete Example," Journal of Political Economy, 112(6), 1181-1222. 


\section{A Tables and Figures}




\begin{tabular}{rrrr} 
Average Shipments (in thousands) & Birth & Continuer & Death \\
\hline \hline 1977 & 461 & 1,164 & 402 \\
1982 & 1,045 & 1,503 & 520 \\
1987 & 1,241 & 2,307 & 601 \\
1992 & 1,509 & 2,218 & 1,417 \\
1997 & 1,559 & 3,293 & 1,358 \\
\hline & & & \\
Average Capital (in thousands) & Birth & Continuer & Death \\
\hline \hline 1977 & 217 & 491 & 185 \\
1982 & 403 & 598 & 187 \\
1987 & 549 & 1,050 & 270 \\
1992 & 565 & 1,131 & 632 \\
1997 & 728 & 1,992 & 770 \\
\hline & & & \\
Average Salaries (in thousands) & Birth & Continuer & Death \\
\hline \hline 1977 & 83 & 211 & 83 \\
1982 & 185 & 269 & 83 \\
1987 & 205 & 413 & 101 \\
1992 & 257 & 428 & 267 \\
1997 & 243 & 567 & 241 \\
\hline \hline
\end{tabular}

Table A1: Characteristics of Plants that are Births, Deaths and Continuers 


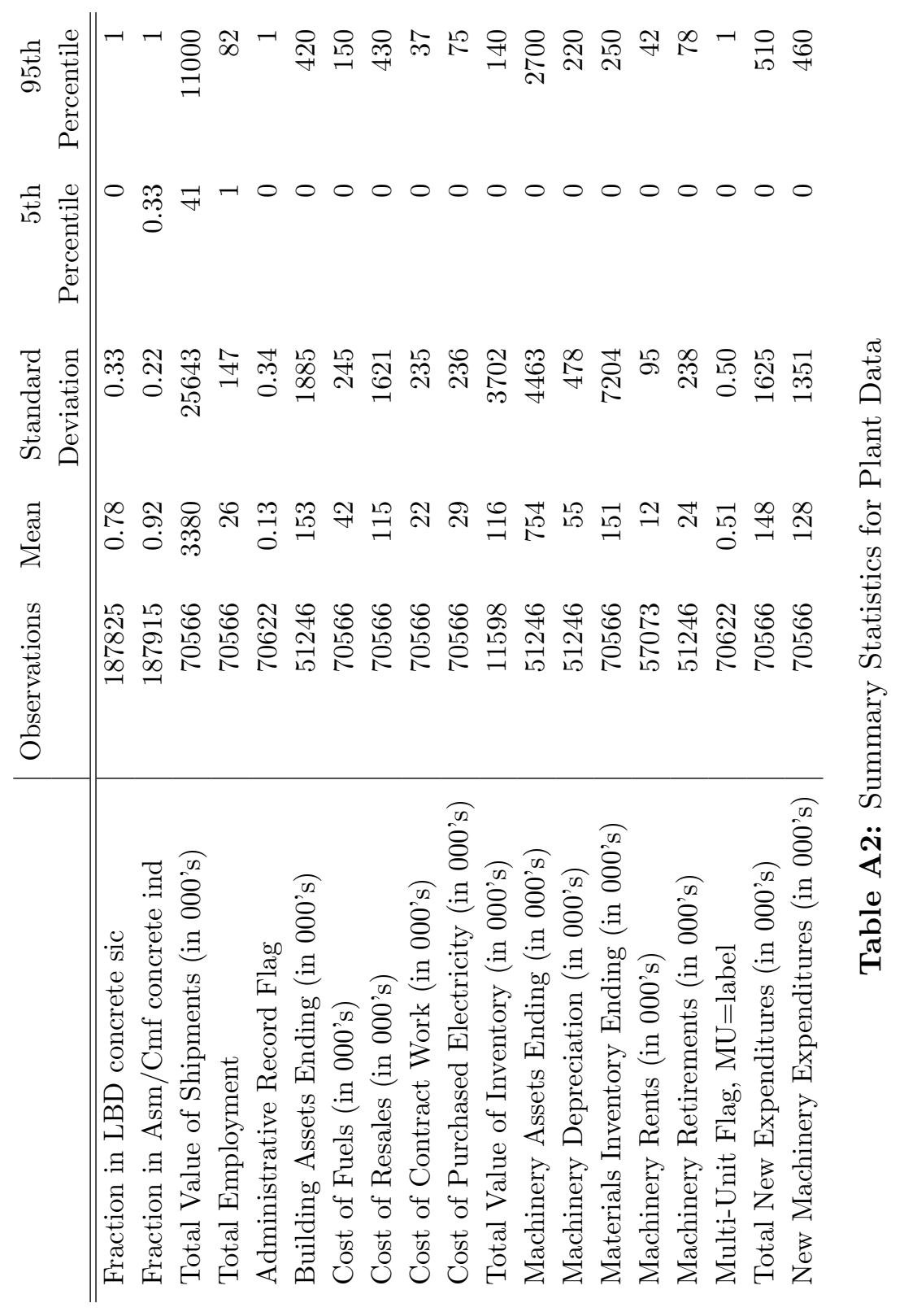




\begin{tabular}{|c|c|c|c|c|c|c|}
\hline \multirow[b]{2}{*}{ Value Added } & \multicolumn{2}{|c|}{ OLS } & \multicolumn{2}{|c|}{ First-Stage Regression } & \multicolumn{2}{|c|}{ "Olley-Pakes Coefficents } \\
\hline & Coefficient & S.E. & Coefficient & S.E. & Coefficient & S.E. \\
\hline Constant & 2.128 & $(0.066)$ & 2.340 & $(0.129)$ & 1.559 & $(0.235)$ \\
\hline Salaries & 0.681 & $(0.008)$ & 0.661 & $(0.010)$ & 0.661 & $(0.010)$ \\
\hline Assets & 0.154 & $(0.007)$ & 0.246 & $(0.049)$ & 0.163 & $(0.010)$ \\
\hline Investment & & & -0.087 & $(0.042)$ & & \\
\hline Squared Assets & & & -0.026 & $(0.010)$ & & \\
\hline Squared Investment & & & 0.025 & $(0.010)$ & & \\
\hline Assets * Investment & & & -0.004 & $(0.004)$ & & \\
\hline Cubed Assets & & & 0.002 & $(0.001)$ & & \\
\hline Cubed Investment & & & -0.001 & $(0.001)$ & & \\
\hline Year Effects & $\mathrm{X}$ & & $\mathrm{X}$ & & $\mathrm{X}$ & \\
\hline $\mathrm{F}$ & 1145 & & 762 & & & \\
\hline $\mathrm{R} 2$ & 0.77 & & 0.80 & & & \\
\hline Observations & 9072 & & 6236 & & & \\
\hline
\end{tabular}

Table A3: Olley-Pakes Production Function Estimates 


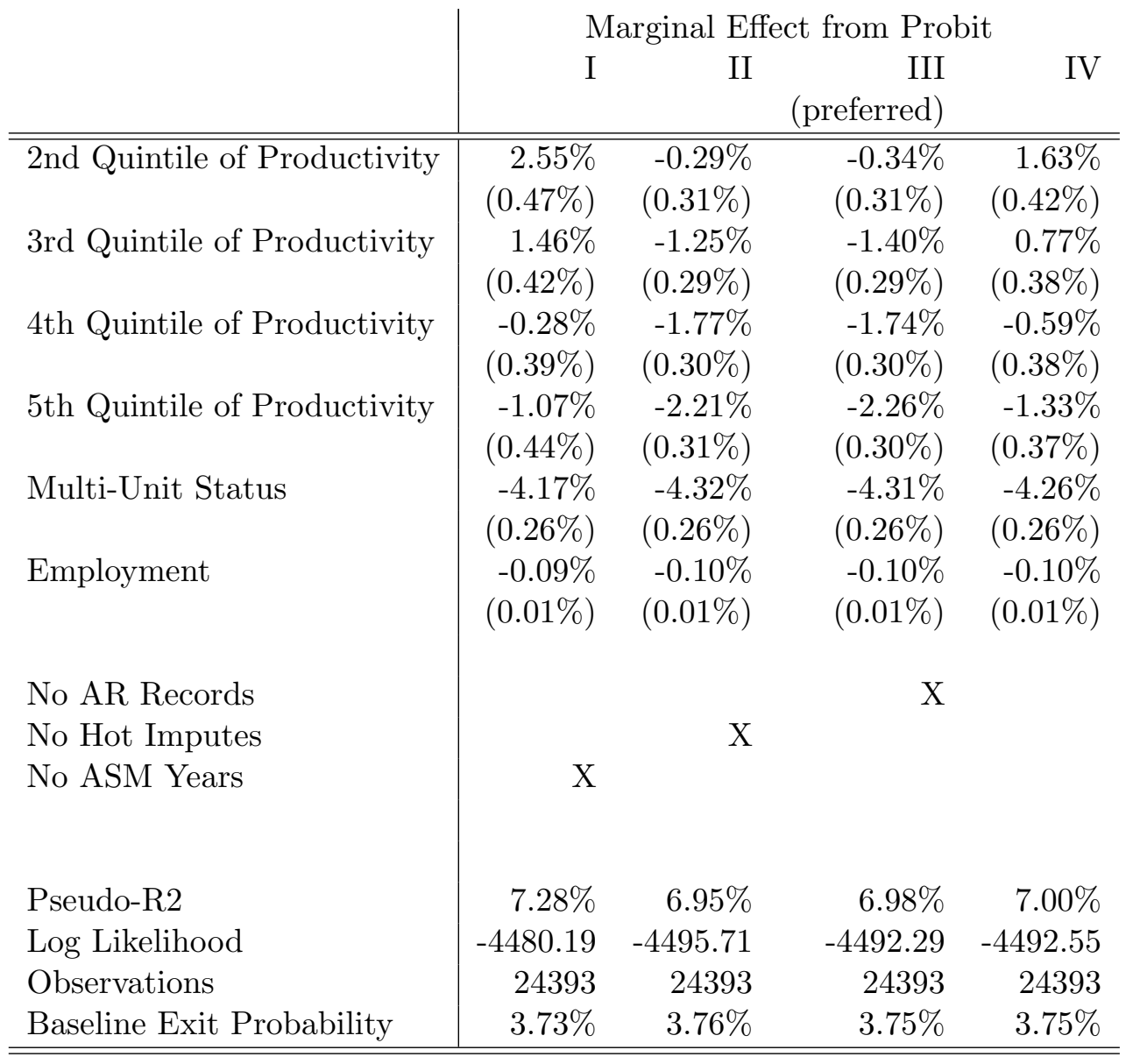

Table A4: The relationship between productivity and exit is monotonic even after controlling for plant characteristics and dropping AR or hot imputes. 
Probit on Exit Decision

Baseline Exit Probability $=2.98 \%$

\begin{tabular}{rr}
$-0.13 \%$ & $0.02 \%$ \\
$2.38 \%$ & $0.29 \%$ \\
$-2.98 \%$ & $0.20 \%$ \\
$1.66 \%$ & $0.25 \%$ \\
$0.28 \%$ & $0.28 \%$ \\
$-2.66 \%$ & $0.47 \%$ \\
$0.03 \%$ & $0.01 \%$ \\
$0.01 \%$ & $0.00 \%$ \\
$0.03 \%$ & $0.03 \%$ \\
Yes & \\
\hline & \\
$8.41 \%$ & \\
-5716 & \\
\hline
\end{tabular}

Table A5: A plant at the lowest percentile of productivity has twice the probability of exiting as a plant in the highest percentile of productivity. 
County Fixed-Effect Negative Binomial Regression

\begin{tabular}{lrr}
\hline \hline & 29670 & \\
Number of observations & 1777 & \\
Number of groups & -6223 & \\
Log likelihood & & \\
& Coefficient & Standard Error \\
& & \\
Plant Births in a county & 1.22 & 0.08 \\
& -0.54 & 0.10 \\
Fraction of Plants with less than 10 employees & -0.12 & 0.12 \\
Fraction of Plants with more than 25 employees & -0.66 & 0.10 \\
Fraction of Plants in the lowest tercile of productivity & -0.42 & 0.10 \\
Fraction of Plants in the top tercile of productivity & -0.97 & 0.04 \\
Fraction of Plant that exit this period & 0.00 & 0.04 \\
Log of Employment in the Concrete Sector & 1.01 & 0.03 \\
Change in Log of Employment in the Construction Sector & -0.34 & 0.15 \\
Change in Log of Employment in the Concrete Sector & 9.17 & 0.40 \\
Log of Employment in the Construction Sector & 0.05 & 0.01 \\
Log of Concrete Plants in the county & -1.53 & 0.14 \\
Square of Log of Employment in Construction Sector & & \\
Square of Log of Concrete Plants & Yes & \\
& 10.29 & 94.54 \\
\hline Year Fixed Effects & & \\
Constant &
\end{tabular}

Table A6: The presence of productive plants deters entry. 


\begin{tabular}{|c|c|c|c|}
\hline Market Size Category & Median Number of Plants & Productivity & Share of Plants \\
\hline \multirow[t]{3}{*}{1} & $\begin{array}{ll} & 1\end{array}$ & Low Productivity* & $41 \%$ \\
\hline & & Medium Productivity** & $33 \%$ \\
\hline & & High Productivity*** & $24 \%$ \\
\hline \multirow[t]{3}{*}{2} & 3 & Low Productivity & $37 \%$ \\
\hline & & Medium Productivity & $32 \%$ \\
\hline & & High Productivity & $31 \%$ \\
\hline \multirow[t]{3}{*}{3} & 5 & Low Productivity & $29 \%$ \\
\hline & & Medium Productivity & $34 \%$ \\
\hline & & High Productivity & $37 \%$ \\
\hline \multirow[t]{6}{*}{4} & 16 & Low Productivity & $20 \%$ \\
\hline & & Medium Productivity & $34 \%$ \\
\hline & & High Productivity & $46 \%$ \\
\hline & * Lowest tercile of product & vity & \\
\hline & ** Medium tercile of prod & ctivity & \\
\hline & $* * *$ Highest tercile of produ & ctivity & \\
\hline
\end{tabular}

Table A7: In large markets a higher fraction of plants are productive. 


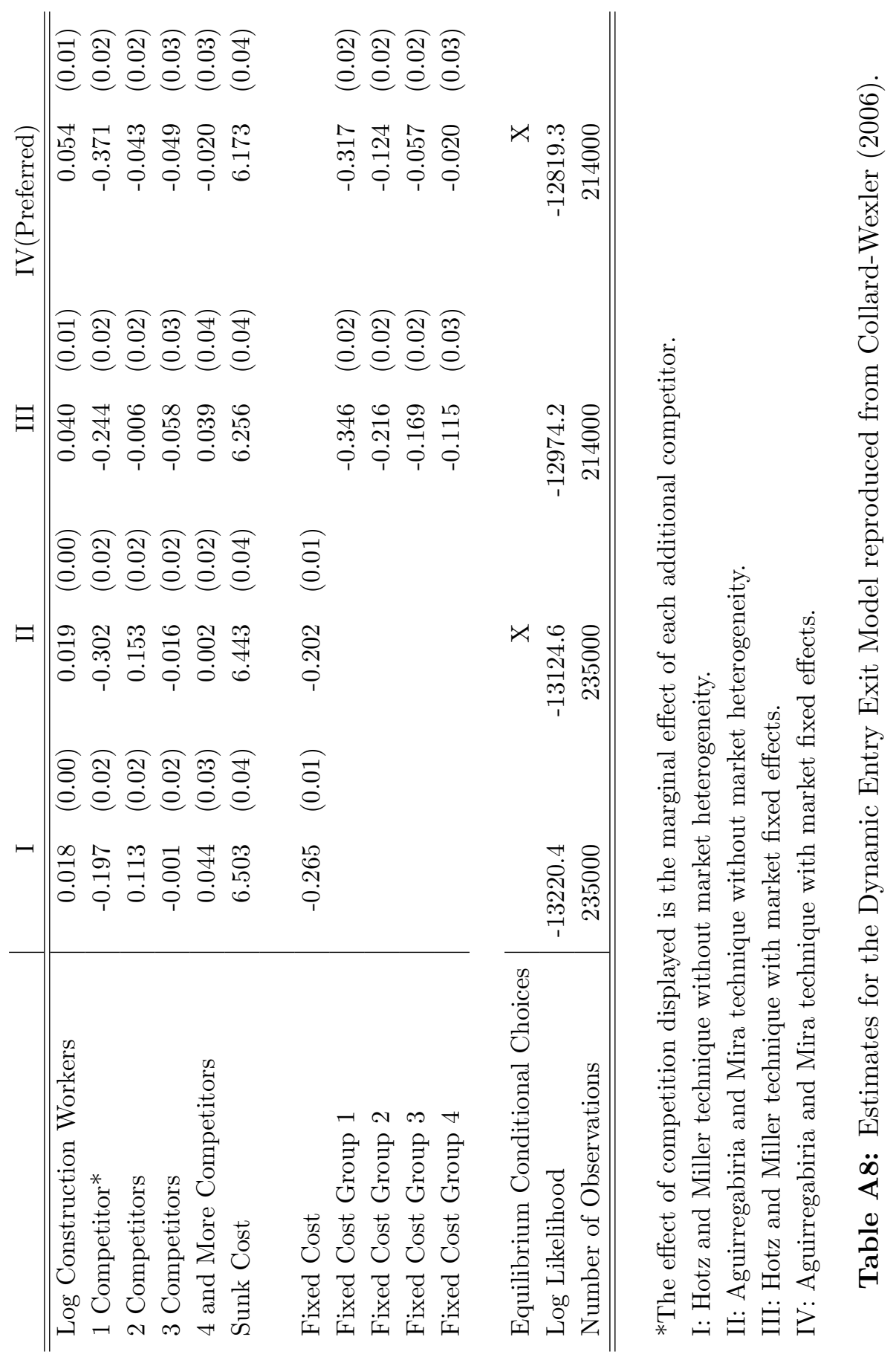


Productivity and Exit

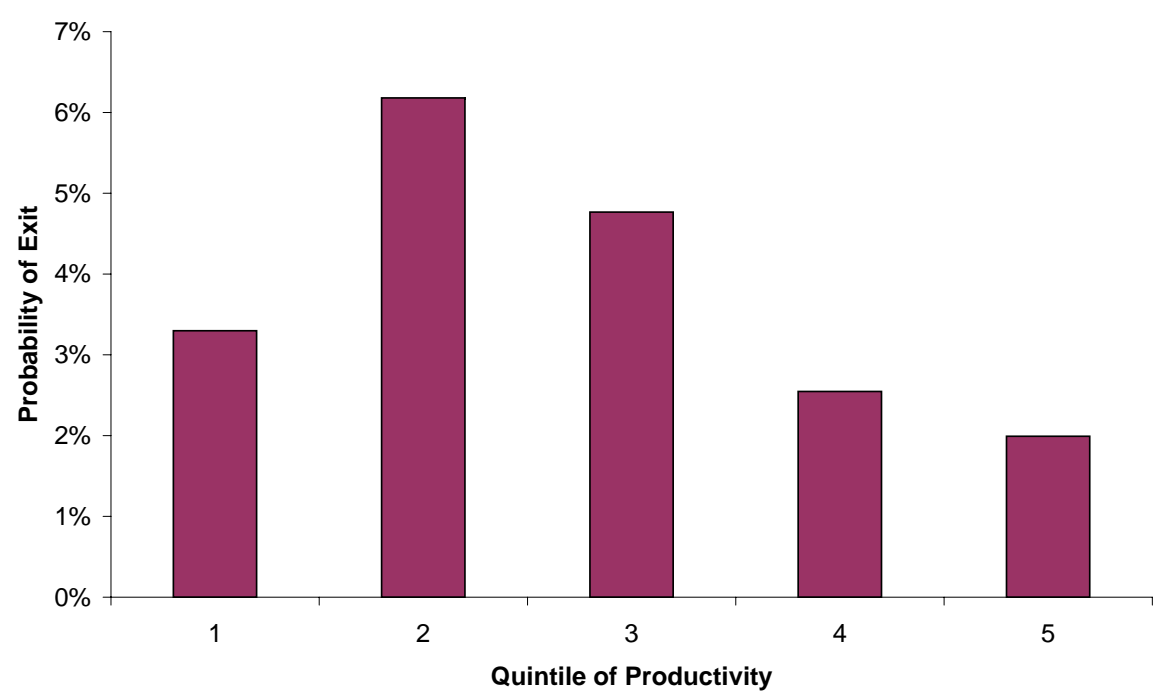

Figure A1: More productive plants have a lower likelihood of exit, more or less.

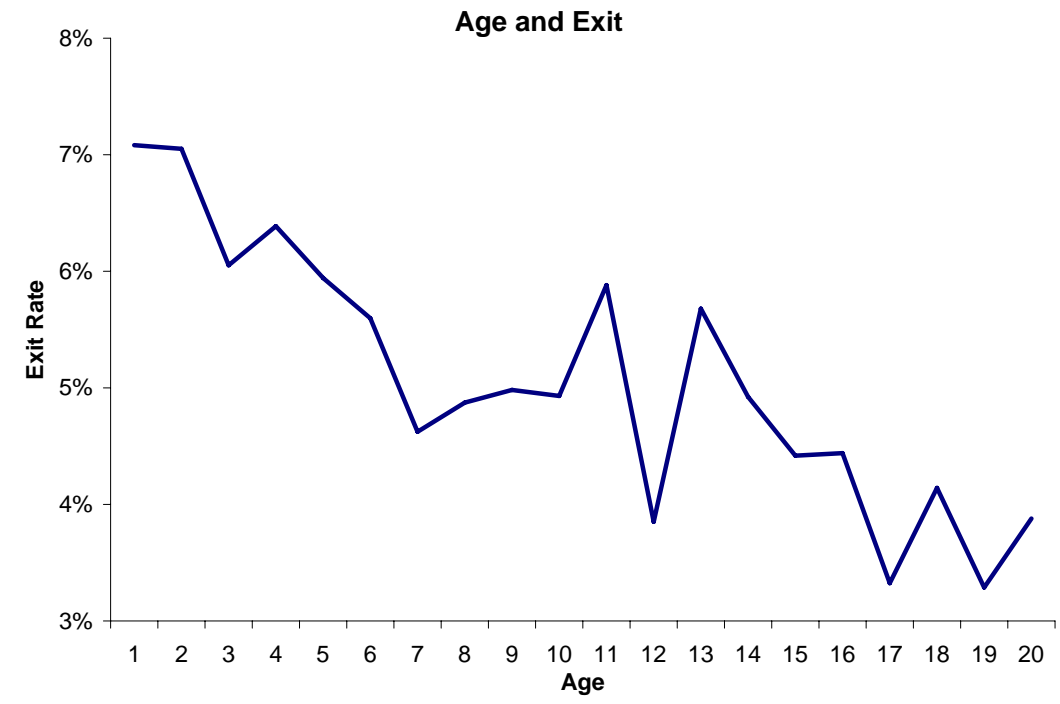

Figure A2: Older firms are slightly less likely to exit. 
Age and Productivity

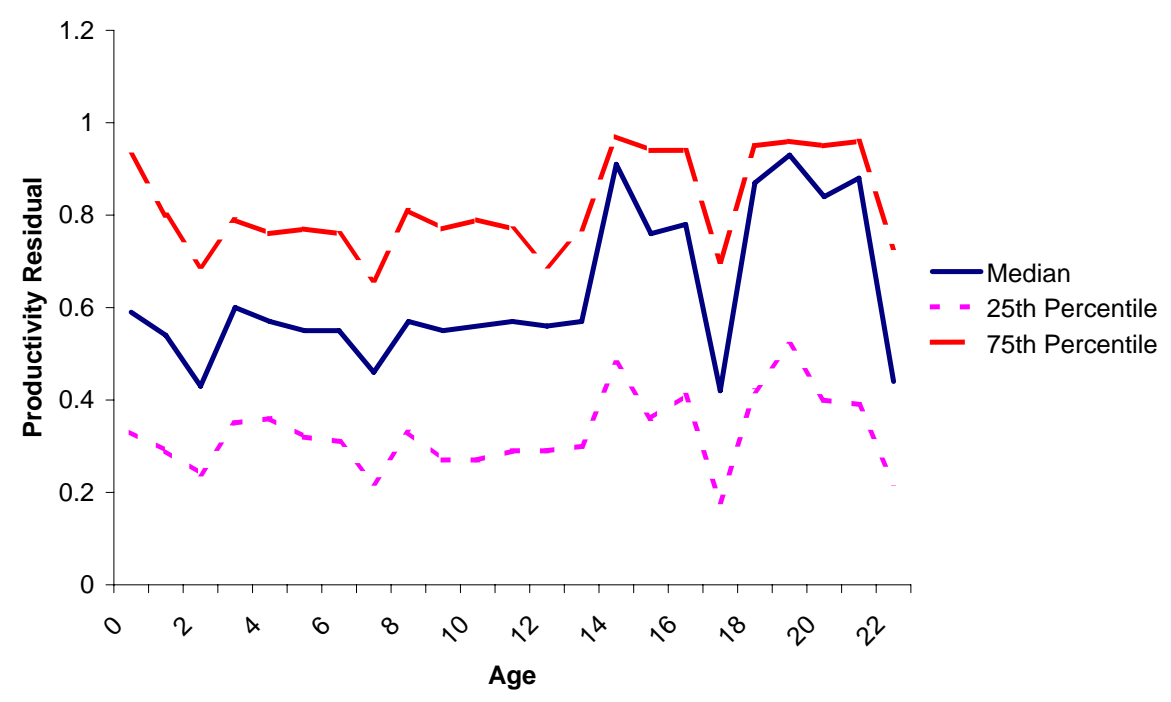

Figure A3: Plant Productivity shows little change as it ages.

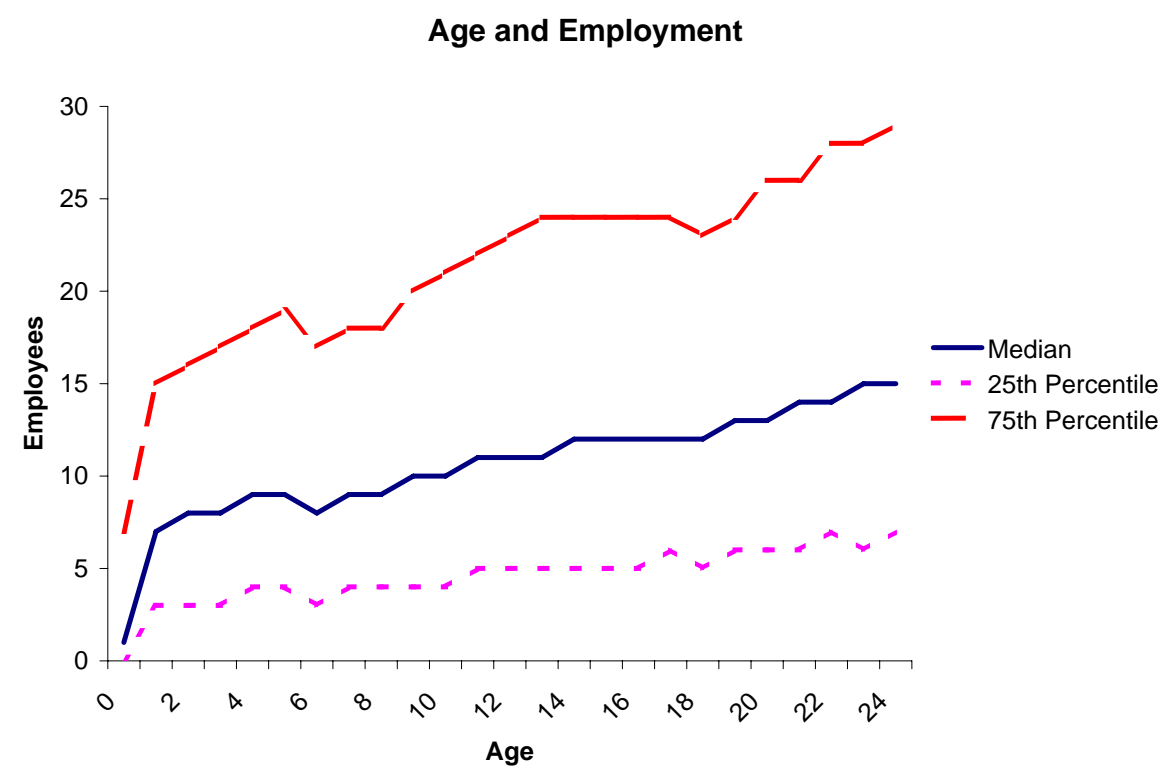

Figure A4: Average plant employment rise slowly after the first year in operation. 


\section{B Imputed Data}

Census imputes data in three ways: 17

1. Administrative Records (AR): Plants with fewer than 5 employees are deemed administrative record (henceforth AR), i.e. they do not have to respond to Census questionnaires. The CMF imputes data for AR records, about $30 \%$ of ready-mix concrete plants, but far less than the $\frac{2}{3}$ plants missing in the ASM. Their data is imputed based on the number of employees at the plant. It is impossible to know if very small producers are productive or not. To estimate the dynamic model, I use imputed values of productivity for AR plants.

2. Cold Deck Imputes: If a plant does not respond to a particular question on the ASM or CMF, their response can be imputed by taking the response for the average plant and scaling it by the number of employees at a plant.

3. Hot Deck Imputes: Another way to impute data is to assign a plant the same level of capital, labor and output as another plant with similar characteristics, such as the same number of employees. This imputation technique is known as hot deck imputation.

Administrative Records are flagged in Census Datasets, but hot and cold deck imputes are not. Therefore, I need to identify observations which contain either hot or cold deck imputes.

To eliminate hot deck imputes, I flag all plants in a given year that have identical capital, salaries and value added. Each of these observations is classified as hot deck impute I cannot identify the original observation that was for the imputed observation. Likewise, for cold deck imputes I flag all plants with the same capitallabor ratio as the mode for that year as a cold deck impute 18 Falsely classifying an observation as cold deck impute is unlikely since the probability that a real observation has the same capital-labor ratio as the mode for the year is quite small. Table A9 shows the number of observations in CMF and ASM data that are Administrative Records, Hot Deck imputes and data collected by the ASM. About $40 \%$ of the data is imputed.

Table A10 shows production function estimates using value added as a plant's output, where I alternatively drop administrative records, cold and hot deck imputes and ASM years. Dropping imputed data from the sample has little effect on estimated coefficients but increases the variance of the productivity residual. Dropping imputed data does not change the coefficients of the productivity regression. However, imputed observations are assigned the mean capital-labor-shipment ratio, increasing overall "fit" and lowering implied productivity dispersion. However, if I include data from ASM years the coefficient on labor rises from 0.6 to over 0.8 and

\footnotetext{
${ }^{17}$ The discussion of stripping imputes from Census data draws heavily on Syverson (2004).

${ }^{10}$ An observation is classified as a cold deck impute if $\left|K_{i}^{t} / L_{i}^{t}-\operatorname{mode}(K / L)^{t}\right|<0.001$ where $K_{i}^{t}$ and $L_{i}^{t}$ denote plant $i$ 's capital and salaries in year $t$.
} 


\begin{tabular}{l|r} 
Impute Flag & Number of Observations \\
\hline \hline Administrative Records & 7231 \\
Hot Imputes & 6277 \\
ASM year data & 8217 \\
\hline Total Observations with capital, & \\
salary and shipments data & $37559^{20}$
\end{tabular}

Table A9: A large fraction of Census of Manufacturing and Annual Survey of Manufacturers data is imputed.

the capital coefficient falls from 0.3 to 0.04 . In addition, plant fixed-effects regression are similar to estimates using only CMF data. Selection does not seem to be a problem in the measurement of productivity, i.e. the fact that more productive plants are more likely to survive and increase their capital stock, since OLS and plant fixed-effect regressions are similar ${ }^{19}$ This indicates that the persistent component of plant-level productivity is uncorrelated with capital stock. loped by Olley and Pakes (1996) and Ackerberg, Frazer, and Caves (2006) to purge simultaneity and selection bias from the model yield similar capital and labor coefficients as OLS using CMF years. This indicates that the persistent component of plant-level productivity is uncorrelated with capital stock.

\footnotetext{
${ }^{19}$ In addition, estimates using techniques developed by Olley and Pakes (1996) and Ackerberg, Frazer, and Caves (2006) to purge simultaneity and selection bias from the model yield similar capital and labor coefficients as OLS using CMF years.
} 


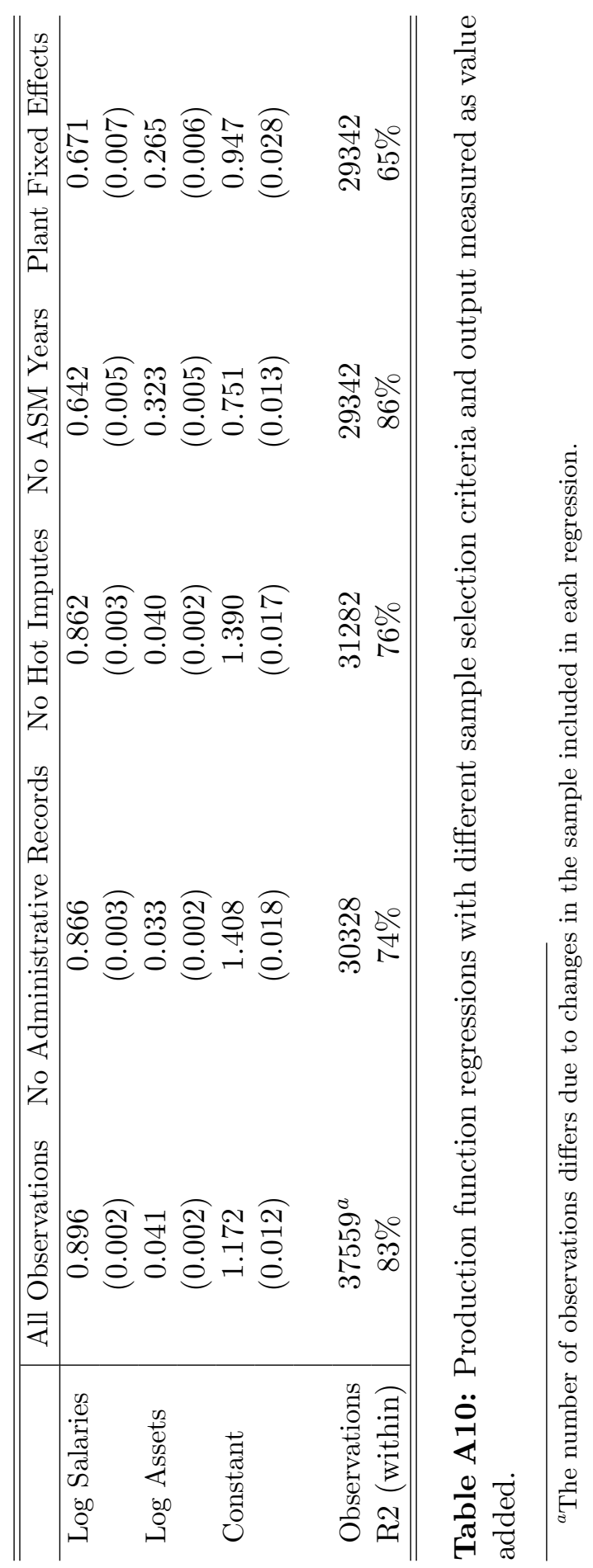




\section{Different Measures of Output in Estimating Pro- duction Functions}

I use three different definitions of output which generate corresponding measures of productivity:

1. Value Added (henceforth VA).

2. Total Value of Shipments (TVS).

3. Cubic Yards of Concrete (CYC).

Productivity residuals generated by these measure of output are somewhat correlated. Measures based on revenues (VA and TVS) are highly correlated. The measure based on quantity (CYC) has a weak correlation with the revenue measures (VA and TVS).

The first measure of productivity is the residual from the log-linear production function OLS regression:

$$
y_{i}^{t}(\text { value added })=\beta_{l} l_{i}^{t}(\text { salaries })+\beta_{k} k_{i}^{t}(\text { capital })+A^{t}+\rho_{i}^{t}
$$

where a lower case variable denotes the logarithm of the actual variable, $A_{t}$ is the intercept of the production function for each year (so that year to year changes in technology do not affect the dispersion of productivity) and $\rho_{i}^{t}$ is a plant's productivity. I deflate all items measured in dollars by the consumer price index (CPI) published by the BLS for the given year ${ }^{2122}$

The second measure of productivity is based on total value of shipments, the KLEM production function:

$$
\begin{aligned}
y_{i}^{t}(\text { total value of shipments })= & \beta_{l} l_{i}^{t}(\text { salaries })+\beta_{k} k_{i}^{t}(\text { capital }) \\
& +\beta_{m} m_{i}^{t}(\text { cost of materials })+A^{t}+\rho_{i}^{t}
\end{aligned}
$$

Finally, I measure productivity based on cubic yards of concrete produced by a plant. This is an effective measure of output for the ready-mix concrete industry since ready-mix concrete is a homogeneous good and ready-mix concrete is a plant's sole output: ${ }^{23}$

$$
\begin{aligned}
q_{i}^{t}(\text { cubic yards of concrete })= & \beta_{l} l_{i}^{t}(\text { salaries })+\beta_{k} k_{i}^{t}(\text { capital }) \\
& +m_{i}^{t}(\text { materials })+A^{t}+\rho_{i}^{t}
\end{aligned}
$$

\footnotetext{
${ }^{21}$ It is important to deflate data measured in dollars since the log-linear production function is not linearly homogeneous if the sum of the capital and labor coefficients differs from one, and thus is sensitive to rescaling variables.

${ }^{22} \mathrm{CPI}$ data downloaded from ftp://ftp.bls.gov/pub/special.requests/cpi/cpiai.txt, accessed May 52006.

${ }^{23}$ See Collard-Wexler (2006) for evidence on the preponderance of ready-mix concrete in a plant's output.
} 


\begin{tabular}{l|ccc} 
& \multicolumn{3}{|c}{ Output Measure } \\
\hline \hline \multirow{3}{*}{ Log Salaries } & Log Value Added & Log Shipments & Log Cubic Yards of Concrete \\
& 0.633 & 0.270 & 0.138 \\
Log Assets & $(0.006)$ & $(0.003)$ & $(0.012)$ \\
& 0.269 & 0.116 & 0.084 \\
Log Materials & $(0.006)$ & $(0.003)$ & $(0.010)$ \\
& & 0.587 & 0.689 \\
Constant & 1.163 & $(0.003)$ & $(0.011)$ \\
& $(0.022)$ & 1.170 & 4.366 \\
Observations & 22114 & $(0.011)$ & $0.042)$ \\
R2 & $74 \%$ & 21941 & 15636 \\
\hline \hline
\end{tabular}

Table A11: Production function regressions with different output measures.

Table A11 presents production function regressions with output defined as value added (VA), total shipments (TVS) or volume of ready-mix concrete (CYC). Notice that the TVS and CYC regressions have similar coefficients for materials, capital and labor. One might worry that the total value of shipments mismeasures output. Prices are higher in more concentrated markets, and thus the value of shipments will also be higher ${ }^{24}$ The total volume of concrete produced can also mismeasure output, since ready-mix concrete trucks do not need to drive as far in denser markets to make a delivery. A plant located in a dense market can economize on trucks, drivers and fuel giving the (mistaken) appearance that it is a more efficient operation. The "fit" of the regression as measured by the $R^{2}$ is much higher for the total shipments regression than the cubic yards of concrete regression. Moreover, capital and labor coefficients are higher in the shipments regression than in the volume regression. This could indicate either that different types of concrete require different levels of inputs, or that the price level for concrete is correlated with the price level for labor and capital (perhaps in the form of higher land prices for the latter).

Table A12 shows that the correlation between the three measures of productivity varies greatly. Productivities measured using value added and total shipments are highly correlated. The correlation between these measures and those with output defined as cubic yards of concrete is fairly low. The way in which productivity is measured is quite important. In the subsequent sections, productivity refers to residual from the value added regression with ASM years omitted (column 3 of

\footnotetext{
${ }^{24}$ Figure A2 in Collard-Wexler (2006) presents illustrates higher prices in markets with fewer plants.
} 


\section{Correlation Matrix}

\begin{tabular}{l|lll} 
Productivity Residuals from Table A11 & Value Added & Shipments & $\begin{array}{l}\text { Cubic Yards } \\
\text { of Concrete }\end{array}$ \\
\hline Value Added & 1 & & \\
Shipments & 0.88 & 1 & 1 \\
Cubic Yards of Concrete & 0.25 & 0.18 &
\end{tabular}

Table A12: Measures of productivity based on sales are highly correlated with each other, but are fairly uncorrelated with measures of productivity based cubic yards of concrete shipped.

Table A10 and column 1 of Table A11.

\section{Determinants of Productivity Volatility}

It is a tautology that changes in productivity are caused by change in valued added, labor or capital. Table A13 displays the autocorrelation of valued added, salaries and total assets. Value added and salaries have autocorrelations above $90 \%$. The autocorrelation of total assets is only $70 \%$, which is surprising since in the short-run capital is harder to change than labor ${ }^{25}$ I conjecture that capital assets are volatile because of measurement error, not because of the technology used to produce concrete. A manager can easily compute the total wage bill and revenue collected during the year. Reckoning the book value of assets is difficult without meticulous accounting of the purchase price of capital assets. The correlation between assets at the start of the year and at the end of the year is above $90 \%$ while the correlation across years is $70 \%$. This suggests that either managers do most of their capital purchases on January 1st or that there is error in measuring capital stock. Measurement error would produce underestimates of the persistence of plant-level productivity. As well, mismeasurement of productivity would lead to attenuation bias for productivity in a plant's decision to exit, explaining the small correlation between productivity and exit that I report in the next section.

To correct for the problem of capital volatility, I construct a measure of capital stock based on investment flows and depreciation. In practice, capital stock tomorrow is computed recursively as:

$$
f k^{t+1}=f k^{t}-\underbrace{d^{t}}_{\text {depreciation }}+\underbrace{i^{t}}_{\text {investment }}
$$

where I call $f k$ flowcapital. I replace $f k^{t}$ with $k^{t}$, the actual capital stock, when

\footnotetext{
${ }^{25}$ It is easy to change labor in the ready-mix concrete industry since (at least for Illinois) labor contracts do not specify hours per worker. Instead employees are called in for work on days when they are needed.
} 


\begin{tabular}{l|rrr} 
& Correlation Matrix & & \\
& Log Assets & Log Salaries & Log Shipments \\
\hline Log Assets & 1 & & \\
Lagged Log Assets & 0.73 & & \\
& & & \\
Log Salaries & 0.47 & 0.91 & 1 \\
Lagged Log Salaries & 0.43 & & 0.92 \\
& & 0.89 &
\end{tabular}

Table A13: Total shipments and salaries are highly autocorrelated but capital assets are not.

I cannot construct last period's flowcapital stock since either capital, depreciation or investment are missing. The autocorrelation of flowcapital is 0.99 , versus 0.72 for measured capital stock. Thus this technique of constructing capital stock removes a large amount of the year to year variation in capital. I can then reestimate the production function using flowcapital instead of capital. Table ?? shows production function estimates using flowcapital and capital stock. I find similar coefficients on the production function using either flowcapital or capital as my measure of assets. In fact the coefficient on assets is significantly lower when I use the flowcapital measure, at 0.027 instead of 0.070 when I use capital. Moreover, the productivity residual has autocorrelation of 0.72 when I use flowcapital versus an autocorrelation of 0.70 when I use capital as a measure of assets. 


\begin{tabular}{|c|c|c|c|c|}
\hline \multirow[b]{2}{*}{ Log Shipments } & \multicolumn{2}{|c|}{ Capital Stock } & \multicolumn{2}{|c|}{ Flow Capital Stock } \\
\hline & Coefficient & S.E. & Coefficient & S.E. \\
\hline Constant & 1.709 & $(0.033)$ & 1.530 & $(0.271)$ \\
\hline Salaries & 0.271 & $(0.005)$ & 0.283 & $(0.006)$ \\
\hline Assets & 0.070 & $(0.004)$ & 0.027 & $(0.003)$ \\
\hline Materials & 0.595 & $(0.005)$ & 0.618 & $(0.007)$ \\
\hline Year Effect & $\mathrm{X}$ & & $\mathrm{X}$ & \\
\hline Autocorrelation of Residual & 0.70 & & 0.72 & \\
\hline $\mathrm{F}$ & 5355 & & 1247.46 & \\
\hline $\mathrm{R} 2$ & 0.9413 & & 0.876 & \\
\hline Plants & & & 4256 & \\
\hline Observations & 9049 & & 9049 & \\
\hline
\end{tabular}

Table A14: Flowcapital (capital constructed using investment and depreciation) and measured capital give similar productivity volatility. 